\title{
An intercontinental comparison of chironomid palaeotemperature inference models: Europe vs North America
}

\author{
André F. Lotter ${ }^{\mathrm{a}, \mathrm{b}, *}$, Ian R. Walker ${ }^{\mathrm{a}, \mathrm{c}, \mathrm{d}}$, Stephen J. Brooks ${ }^{\mathrm{e}}$ and Wolfgang Hofmann ${ }^{\mathrm{f}}$ \\ ${ }^{\mathrm{a}}$ Geobotanical Institute, University of Bern, Altenbergrain 21, CH-3013 Bern, Switzerland \\ ${ }^{\mathrm{b}}$ Swiss Federal Institute of Environmental Science and Technology (EAWAG), CH-8600 Dübendorf, Switzerland \\ ${ }^{\mathrm{C}}$ Department of Biology, Okanagan University College, 3333 College Way, Kelowna, British Columbia, Canada V1V 1 V7 \\ ${ }^{\mathrm{d} D e p a r t m e n t}$ of Biological Sciences, Simon Fraser University, Burnaby, British Columbia, Canada V5A 1S6 \\ ${ }^{\mathrm{e}}$ Department of Entomology, The Natural History Museum, Cromwell Road, London SW7 5BD, UK \\ ${ }_{\mathrm{f}}^{\mathrm{f}}$ Max-Planck-Institut für Limnologie, August-Thienemann-Strasse 2, D-24302 Plön, Germany
}

\begin{abstract}
Chironomid-temperature inference models based on North American, European and combined surface sediment training sets were compared to assess the overall reliability of their predictions. Between 67 and $76 \%$ of the major chironomid taxa in each data set showed a unimodal response to July temperature, whereas between 5 and $22 \%$ of the common taxa showed a sigmoidal response. July temperature optima were highly correlated among the training sets, but the correlations for other taxon parameters such as tolerances and weighted averaging partial least squares (WA-PLS) and partial least squares (PLS) regression coefficients were much weaker. PLS, weighted averaging, WA-PLS, and the Modern Analogue Technique, all provided useful and reliable temperature inferences. Although jack-knifed error statistics suggested that two-component WA-PLS models had the highest predictive power, intercontinental tests suggested that other inference models performed better. The various models were able to provide good July temperature inferences, even where neither good nor close modern analogues for the fossil chironomid assemblages existed. When the models were applied to fossil Lateglacial assemblages from North America and Europe, the inferred rates and magnitude of July temperature changes varied among models. All models, however, revealed similar patterns of Lateglacial temperature change. Depending on the model used, the inferred Younger Dryas July temperature decrease ranged between 2.5 and $6{ }^{\circ}$ C. (C) 1999 Elsevier Science Ltd. All rights reserved.
\end{abstract}

\section{Introduction}

Recently, several papers have explored the potential of fossil chironomids as Quaternary palaeotemperature indicators (Lotter et al., 1997; Olander et al., 1997; Walker et al., 1997), and several other studies of a similar nature are currently in progress (Brooks and Birks, unpublished; Levesque et al., unpublished; Porinchu et al., unpublished). These analyses of the distributions of Holarctic chironomids with respect to temperature, and other studies (e.g. Rossaro, 1991; Walker and MacDonald, 1995;

\footnotetext{
*Correspondence address: Geobotanical Institute, University of Bern, Altenbergrain 21, CH-3013 Bern, Switzerland. Tel.: 004131631 4932; fax: 004131332 2059; e-mail: lotter@sgi.unibe.ch.
}

Walker and Mathewes, 1989), indicate many common trends in the data, despite the great geographic separation of the study sites. For example, the abundance of the Chironomini in warm waters, and the predominance of the Orthocladiinae in cold habitats has frequently been noted. These similarities are readily apparent at both the generic and subfamily levels, but the difficulty of identifying larval chironomids to the species level has precluded any comparisons with a higher taxonomic resolution.

Present-day ecologists do not accept the assertion that all members of a chironomid genus can be considered to be ecological equivalents. Nevertheless, because of the similarities in chironomid distribution patterns among regions, Walker et al. (1991a) suggested that chironomids might be particularly robust palaeotemperature 
indicators. Indeed, comparisons of the Nearctic and Palaearctic faunas (e.g. Sæther, 1979) reveal that many of the same species are present in both faunal regions. Where one indicator species is absent, it is frequently replaced by a sister species with similar environmental requirements.

It should also be noted, however, that the Nearctic and Palaearctic faunas have been greatly altered by both natural and anthropogenic environmental changes over the last 13,000 years; thus, it is possible that Lateglacial fossil assemblages may not have present-day analogues in close proximity, or even on the same continent. For example, in continental Europe, high arctic environments no longer exist, and the faunas of many temperate lakes have been greatly disrupted by eutrophication, acidification, and other perturbations to the environment. Thus, we might expect better analogues for the European Lateglacial fauna to occur in present-day North America.

It is with this perspective that we have undertaken a comparison of chironomid-temperature inference models recently developed for North America and Europe. Specifically, we compare air temperature inferences, and ecological optima and tolerances derived from the European and North American models with those obtained from a new, combined surface-sample training set. Analogue matching is used to assess the relevance of these models in reconstructing Lateglacial environments for two sites, one in North America and one in Europe.

\section{Methods}

In this paper, we make use of chironomid assemblage data collected in the course of earlier research. The methods used for surface sample collection, sediment processing, and identification of the subfossils have, therefore, been described in detail in earlier papers (Lotter et al., 1997; Walker et al., 1997). In each case, the chironomid assemblages had been collected from the uppermost lake sediments near the centre, or deepest point in each lake basin, and the sediment had been sorted and pretreated using similar procedures (Walker et al., 1997; Lotter et al., 1997).

To obtain better comparability between the two training sets we used mean July air temperatures as the variable to be reconstructed. Livingstone and Lotter (1998) showed a close relationship between water and air temperatures during the summer months, with the highest correlation for July temperatures. Using air temperatures may circumvent the problem of obtaining useful water temperature measurements from remote high elevation and arctic/subarctic lakes (see, e.g. Hann et al., 1992, Walker et al., 1992). For the Alps the mean July temperature for each site was estimated using a GIS model (Lotter et al., 1997), whereas for the North American data set we estimated mean July temperatures from climate atlases (Thomas, 1953; Houde, 1978; McCalla, 1991). Hereafter, we refer to these estimates as the observed temperatures. Table 1 shows the geographical location, elevation, mean July temperature, and the maximum water depth for the sites used in this study.

Numerical analyses were performed in order to answer the following questions:

(i) What is the relationship between temperature and the response of individual chironomid taxa? To assess the statistical relationship of each individual taxon in the three training sets with regard to July temperature, a hierarchical set of taxon response models was used (see, Huisman et al., 1993). The four response models used were a skewed unimodal response model, a symmetric unimodal response model, a monotonically increasing or decreasing sigmoidal response model, and a null model of no relationship with the environmental variable. Following Lotter et al. (1997) the simplest statistically significant response model for each taxon was found by fitting the most complex model first and progressively removing parameters from the regression model. This was done until the model could not be simplified without a significant change $(p<0.05)$ in the deviance of the model. Taxon response models were fitted by maximum likelihood with a Poisson error structure and a logarithmic link function, and were restricted to all taxa with occurrences in $20 \%$ or more of the samples in the screened training sets.

(ii) Which regression models are able to provide the most reliable inferences with regard to mean July air temperature? To answer this question the chironomid percentage data were transformed to square root values and weighted averaging partial least squares (WA-PLS), weighted averaging (WA), and partial least squares (PLS) regression models were applied using the program CALIBRATE (S. Juggins and C.J.F. ter Braak, unpubl. program). Screening for outliers in the data sets was carried out according to Jones and Juggins (1995) and Lotter et al. (1997).

(iii) How do optima and tolerances of European chironomid taxa compare with the optima and tolerances of the same taxa in the North American data set, and what are the optima and tolerances if the two data sets are merged? Species optima and tolerances were assessed by using WA implemented in the program WACALIB (Line et al., 1994). We also compared the WA-PLS regression coefficients (Beta coefficients) for both data sets, as determined via WA-PLS and PLS regression, using the program CALIBRATE.

(iv) How well does the European model predict the mean July temperature at North American sites, and vice versa? To answer this question we employed WA-PLS, WA, and PLS calibration (ter Braak et al., 1993) to the square-root transformed percentage data by means of the programs WAPLS (ter Braak and Juggins, 1993) and CALIBRATE. 
(v) Does the Modern Analogue Technique (MAT) provide a better alternative for inferring temperatures than regression-based models? Can the North American chironomid assemblages be used as modern analogues for the European data set, and vice versa? Analogue matching was carried out by the program MAT (S. Juggins, unpubl. program), using Chi-squared distance as the dissimilarity coefficient. Here we also used square-root transformed chironomid percentage data, and all samples with a minimum occurrence of at least 40 head capsules. This gave 43 sites and 64 taxa for the North American data set and 58 sites with 42 taxa for the European data set. Following Jones \& Juggins (1995) we used the 2nd percentile of the matrix of dissimilarities between all modern samples to define a close analogue, and the 5th percentile as a good analogue. For July temperature predictions the models that gave the highest coefficients of determination $\left(r^{2}\right)$ and the lowest errors were chosen.

(vi) How similar are the temperature inferences, derived from different training sets and different modelling techniques, when hindcasting mean July air temperatures for fossil chironomid assemblages? The square-root transformed Lateglacial chironomid percentage data from Splan Pond (New Brunswick, Canada), and Whitrig Bog (Scotland) were used as fossil data sets in WA-PLS, WA and PLS calibration, and for analogue matching as carried out by the program MAT. The transfer functions resulting from question (iii) were applied to hindcast past mean July air temperatures.

\section{Results and discussion}

\subsection{Training set merging}

Modern training sets are usually developed for use in specific regions. Merging of different regional training sets may extend the environmental gradient of interest. Moreover, bigger training sets may allow better estimates of species' optima and tolerances in relation to important environmental variables and may also increase the chances for finding good modern analogues for fossil assemblages. Merging regional training sets has, nevertheless, some important disadvantages. With increasing size of the data set the heterogeneity also increases. This increase may be data-inherent and/or caused by taxonomical and methodological inconsistencies (Birks, 1994) often related to the involvement of different analysts. Furthermore, there is the problem of multiple analogues as well as biogeographical differences in species' optima. These factors may lead to a loss of analytical precision or even to misleading results. Taxonomic harmonization and analytical quality control are, therefore, an important issue (e.g. Munro et al., 1990).
We have overcome differences in taxonomic treatment for the original data sets via discussions between the analysts principally responsible for the North American and European data. This taxonomic harmonization of the data sets forced the merger of some chironomid taxa, principally within the subtribe Tanytarsina, and subfamily Orthocladiinae. The original merged data set included 107 sites and 65 taxa. We used samples that contained at least 50 head capsules for regression and calibration purposes. This resulted in 39 sites with 51 different taxa for the North American data set, and 56 sites with 42 taxa for the European data set (see Table 1). With these data we could now study whether a combined, inter-regional data set would perform better than two separate, regional data sets.

\subsection{Temperature response models}

Detrended correspondence analysis (DCA; ter Braak, 1987) with mean July temperature as the sole constraining variable revealed a compositional gradient length of over 2 standard deviations (SD) for all data sets (Table 2), suggesting the use of unimodal methods (see, e.g. Birks, 1995). The taxa in each training set with statistically significant fits to the four response models are given in Table 3.

In the North American data set $70 \%$ of the taxa with occurrences in more that $20 \%$ of the samples had a unimodal (skewed: $44 \%$; symmetric: $26 \%$ ), $22.5 \%$ a sigmoidal response model, and $7.5 \%$ showed no relationship with July temperature (Table 3). In the European training set $67 \%$ of the major taxa had a unimodal (skewed: $19 \%$; symmetric: $48 \%$ ), $5 \%$ a sigmoidal response model, and $28 \%$ no relationship with July temperature. In the combined training set $76 \%$ of the major taxa showed a unimodal (skewed: $20 \%$; symmetric: $56 \%$ ), $12 \%$ a sigmoidal response model, and $12 \%$ no relationship with July temperature.

Visual inspection of the species abundance data suggests that many taxa showing 'no relationship' with July temperature may actually have had bimodal relationships (e.g. Cricotopus and Orthocladius, Corynoneura and Thienemanniella). All these taxonomic units incorporate several species, and it is, therefore, not surprising that they do not display simple unimodal relationships with July temperature.

Although bimodal, or more complex, relationships might be expected in other merged taxa (e.g. Tanytarsina), in many cases, the number of species included in these groups may be so large as to completely obscure the response of individual species.

\subsection{Quantitative inference models: WA, WA-PLS and PLS}

Screening for outlying samples reduced the European training set to 51 sites with a total of 40 taxa (Table 1). 
Table 1a

Data pertaining to the European training set lakes used in this study (for more details see Lotter et al., 1997)

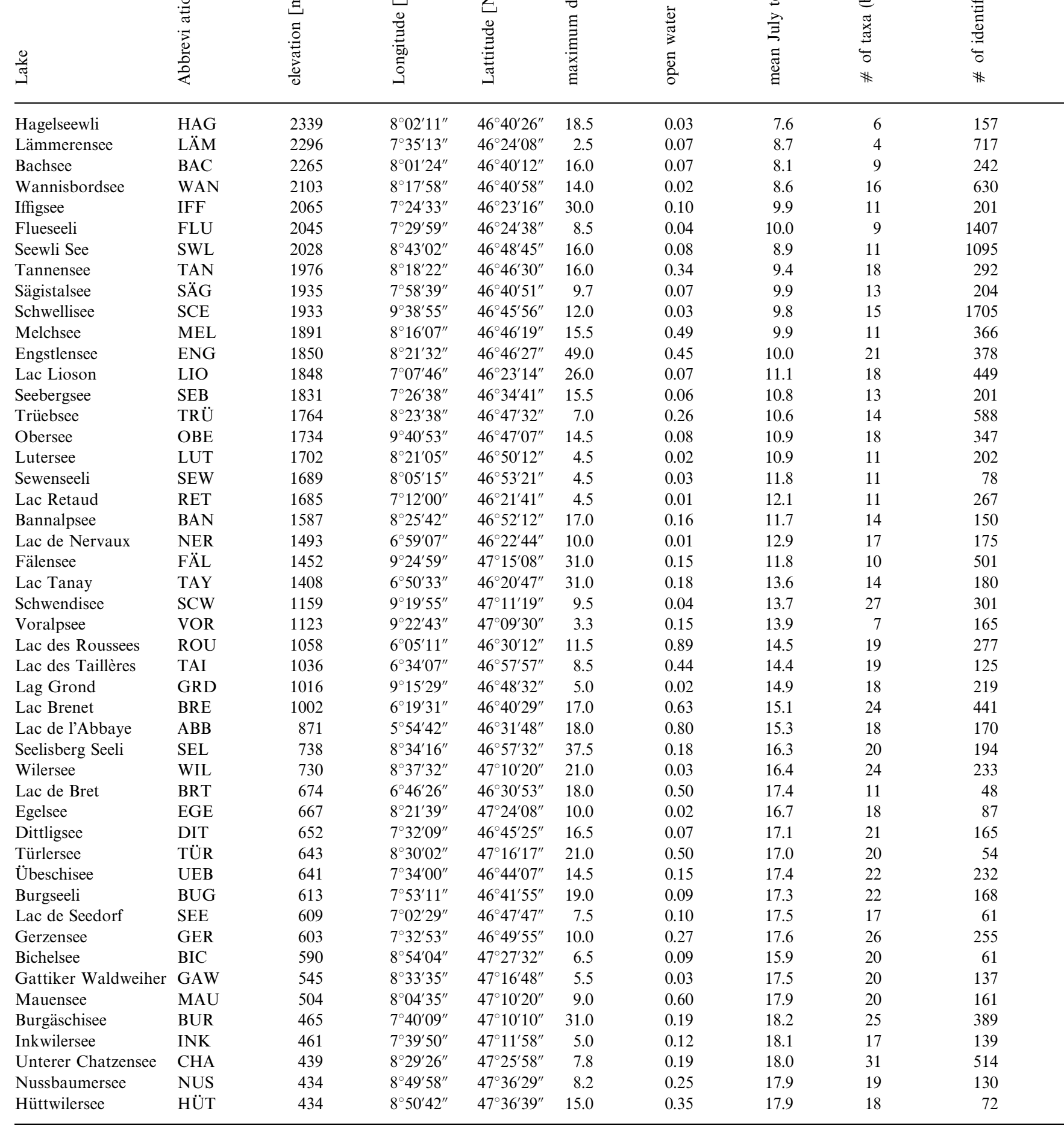




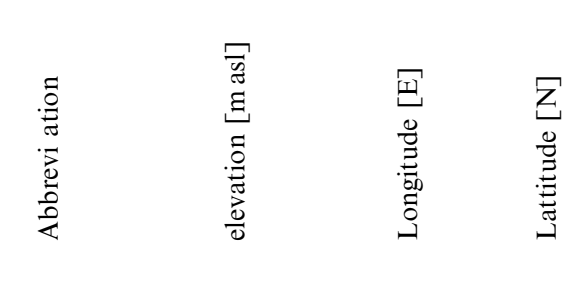

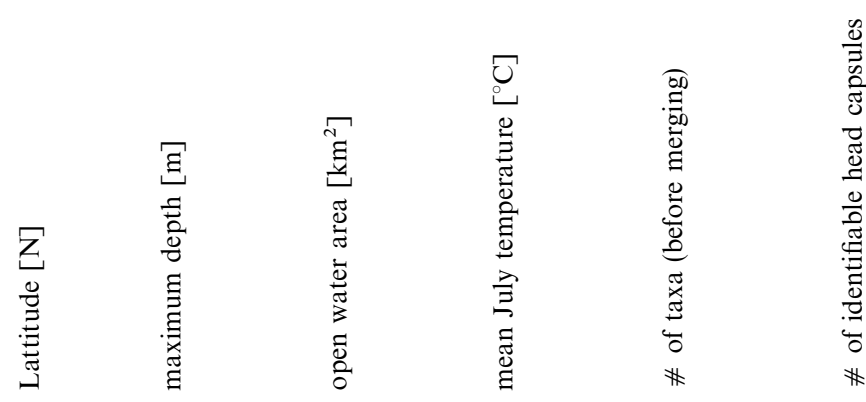

\begin{tabular}{|c|c|c|c|c|c|c|c|c|c|}
\hline Hasensee & HAS & 434 & $8^{\circ} 49^{\prime} 58^{\prime \prime}$ & $47^{\circ} 36^{\prime} 29^{\prime \prime}$ & 5.5 & 0.11 & 17.9 & 20 & 150 \\
\hline Le Loclat & LOC & 432 & $6^{\circ} 59^{\prime} 52^{\prime \prime}$ & $47^{\circ} 01^{\prime} 13^{\prime \prime}$ & 9.2 & 0.05 & 18.3 & 27 & 202 \\
\hline Rotsee & ROT & 419 & $8^{\circ} 19^{\prime} 01^{\prime \prime}$ & $47^{\circ} 04^{\prime} 18^{\prime \prime}$ & 16.0 & 0.50 & 18.3 & 22 & 52 \\
\hline Mettmenhasler See & MET & 418 & $8^{\circ} 29^{\prime} 35^{\prime \prime}$ & $47^{\circ} 28^{\prime} 31^{\prime \prime}$ & 12.5 & 0.03 & 18.1 & 26 & 240 \\
\hline Lago di Montorfano & MON & 394 & $9^{\circ} 08^{\prime} 23^{\prime \prime}$ & $45^{\circ} 46^{\prime} 59^{\prime \prime}$ & 6.5 & 0.52 & 22.5 & 19 & 627 \\
\hline Lago di Segrino & SEG & 374 & $9^{\circ} 16^{\prime} 02^{\prime \prime}$ & $45^{\circ} 49^{\prime} 51^{\prime \prime}$ & 8.5 & 0.34 & 20.6 & 27 & 818 \\
\hline Lago di Muzzano & MUZ & 337 & $8^{\circ} 55^{\prime} 42^{\prime \prime}$ & $45^{\circ} 59^{\prime} 53^{\prime \prime}$ & 3.2 & 0.22 & 21.0 & 16 & 158 \\
\hline Lago di Endine & END & 334 & $9^{\circ} 56^{\prime} 50^{\prime \prime}$ & $45^{\circ} 46^{\prime} 55^{\prime \prime}$ & 8.0 & 0.49 & 21.4 & 17 & 199 \\
\hline Minimum & & 334 & & & 2.5 & 0.01 & 7.6 & 4 & 48 \\
\hline Mean & & 1139 & & & 13.9 & 0.21 & 14.5 & 17 & 317 \\
\hline Median & & 1009 & & & 11.8 & 0.12 & 15.0 & 18 & 202 \\
\hline Maximum & & 2339 & & & 49.0 & 0.89 & 22.5 & 31 & 1705 \\
\hline Standard deviation & & 661 & & & 9.3 & 0.22 & 3.9 & 6 & 318 \\
\hline
\end{tabular}

No outlying samples were identified in the Canadian training set.

Together with the compositional gradient length of $>2$ SD units, as assessed by DCA (Table 2), the fact that over $65 \%$ of the prominent taxa show a unimodal response to July temperature suggests that inference methods based on a unimodal model may perform best with the three training sets. This has also been tested empirically by applying different inference models to the data (Table 2).

As revealed by jack-knifed coefficients of determination $\left(r_{\text {jack }}^{2}\right)$ and root mean squared errors of prediction $\left(\right.$ RMSEP $\left._{\text {jack }}\right)$, simple WA models consistently out-performed WA models with tolerance down-weighting. For the combined and the North American training set linear PLS models performed better than simple WA models. However, all of these models gave consistently lower $r_{\text {jack }}^{2}$ and higher RMSEP jack $_{\text {jan }}$ tha-PLS models using two components. WA-PLS gave a $r_{\text {jack }}^{2}=0.844$ and a RMSEP jack $_{\text {of }} 1.47^{\circ} \mathrm{C}$ for the European training set, with regard to July air temperatures. The two-component WA-PLS model for the North American training set gave a $r_{\text {jack }}^{2}=0.852$ with a $\operatorname{RMSEP}_{\text {jack }}=1.54^{\circ} \mathrm{C}$ (see Table 2).
Despite taxonomic harmonization, resulting in the loss of some taxonomic resolution, comparison of the $r_{\text {jack }}^{2}$ and RMSEP $_{\text {jack }}$, before and after harmonization, revealed that the new models had similar prediction capabilities to those of the original models (see Lotter et al., 1997; Walker et al., 1997). Furthermore, both models give comparable results with regard to predictive power and error estimates. The combined and screened training set includes 90 samples and 57 taxa (Table 2) and produced a somewhat lower $r_{\text {jack }}^{2}(0.813)$ and higher RMSEP $_{\text {jack }}\left(1.74^{\circ} \mathrm{C}\right)$. Nevertheless, these results compare well with published results. For $r^{2}$ they range between 0.58 (Olander et al., 1997) and 0.88 (Walker et al., 1997), whereas the RMSEP lie between $1.37^{\circ} \mathrm{C}$ (Lotter et al., 1997) and $2.26^{\circ} \mathrm{C}$ (Walker et al., 1997). Note, however, that the larger errors reported by Walker et al. (1997) are to some extent related to the larger temperature gradient, and the use of water, rather than air, temperatures.

Although taxonomic harmonization, involving merging of different taxa, generally results in a loss of ecological information (Birks, 1994) this seems not to be a major problem in the case of these two data sets. The taxonomic units distinguished in fossil chironomid analysis represent already groups of species that, from a morphological 
Table $1 b$

Data pertaining to the North American training set lakes used in this study (for more details see Walker et al., 1997)

$\frac{\mathscr{2}}{\sqrt[\pi]{3}}$
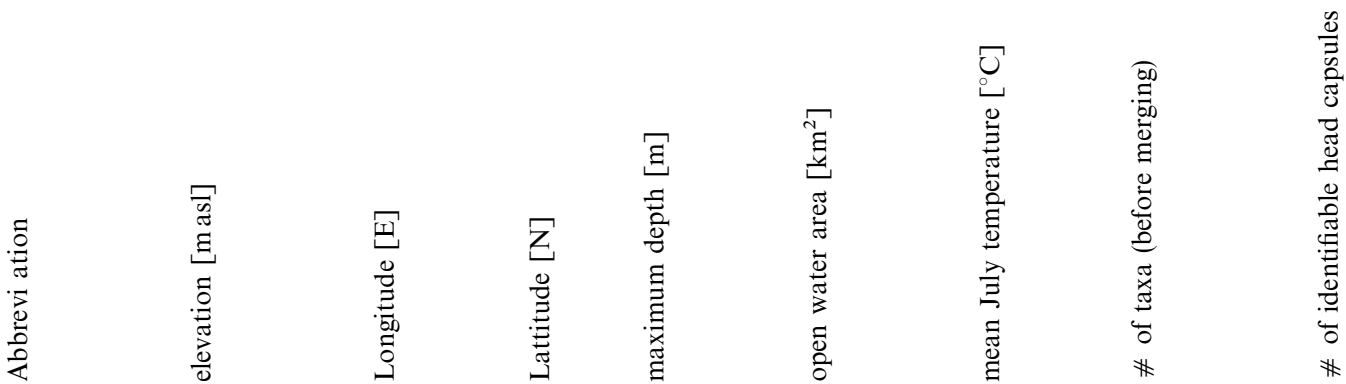

\begin{tabular}{|c|c|c|c|c|c|c|c|c|c|}
\hline Immerk Lake & IMM & 30 & $84^{\circ} 34^{\prime}$ & $75^{\circ} 41^{\prime}$ & 6.8 & 1.05 & 5.0 & 10 & 49.5 \\
\hline $\begin{array}{l}\text { Middle Beschel } \\
\text { Lake }\end{array}$ & $\mathrm{MBE}$ & 30 & $84^{\circ} 28^{\prime}$ & $75^{\circ} 39^{\prime}$ & 8.1 & 0.45 & 5.0 & 11 & 50.5 \\
\hline Phalarope Lake & PHA & 30 & $84^{\circ} 37^{\prime}$ & $75^{\circ} 39^{\prime}$ & 5.0 & 1.57 & 5.0 & 7 & 81.5 \\
\hline Fish Lake & FIS & 30 & $84^{\circ} 32^{\prime}$ & $75^{\circ} 39^{\prime}$ & 4.5 & 0.97 & 5.0 & 9 & 54.5 \\
\hline Lake INSTAAR & INS & 10 & $66^{\circ} 16^{\prime}$ & $62^{\circ} 16^{\prime}$ & 10.0 & 0.52 & 6.7 & 12 & 117 \\
\hline Lake Mercer & MER & 1 & $66^{\circ} 15^{\prime}$ & $62^{\circ} 16^{\prime}$ & 10.0 & 0.38 & 6.7 & 9 & 103.5 \\
\hline L46 & L46 & 479 & $62^{\circ} 48^{\prime}$ & $57^{\circ} 20^{\prime}$ & 22.0 & 0.70 & 7.7 & 9 & 57 \\
\hline L68 & L68 & 500 & $62^{\circ} 55^{\prime}$ & $57^{\circ} 20^{\prime}$ & 9.0 & 0.59 & 8.0 & 4 & 21.5 \\
\hline L45 & L45 & 410 & $63^{\circ} 08^{\prime}$ & $57^{\circ} 17^{\prime}$ & 24.0 & 0.54 & 7.5 & 7 & 57.5 \\
\hline L48 & L48 & 260 & $62^{\circ} 46^{\prime}$ & $57^{\circ} 15^{\prime}$ & 15.0 & 1.03 & 8.0 & 4 & 12 \\
\hline L43 & L43 & 485 & $63^{\circ} 05^{\prime}$ & $57^{\circ} 08^{\prime}$ & 48.5 & 1.68 & 7.8 & 9 & 63 \\
\hline L49 & L49 & 530 & $64^{\circ} 09^{\prime}$ & $56^{\circ} 42^{\prime}$ & 14.0 & 0.86 & 9.0 & 3 & 5 \\
\hline L50 & L50 & 508 & $64^{\circ} 32^{\prime}$ & $56^{\circ} 39^{\prime}$ & 9.0 & 0.57 & 10.0 & 12 & 154 \\
\hline L52 & L52 & 510 & $64^{\circ} 30^{\prime}$ & $56^{\circ} 35^{\prime}$ & 11.0 & 0.84 & 10.0 & 4 & 15 \\
\hline L53 & L53 & 460 & $64^{\circ} 15^{\prime}$ & $56^{\circ} 22^{\prime}$ & 9.0 & 0.86 & 10.2 & 7 & 49.5 \\
\hline L54 & L54 & 480 & $63^{\circ} 57^{\prime}$ & $56^{\circ} 17^{\prime}$ & 3.0 & 1.14 & 10.5 & 17 & 345.5 \\
\hline L56 & L56 & 470 & $64^{\circ} 25^{\prime}$ & $56^{\circ} 10^{\prime}$ & 6.0 & 0.57 & 10.5 & 18 & 254.5 \\
\hline L36 & L36 & 575 & $62^{\circ} 44^{\prime}$ & $55^{\circ} 12^{\prime}$ & 3.0 & 0.59 & 12.0 & 14 & 67.5 \\
\hline L35 & L35 & 569 & $62^{\circ} 44^{\prime}$ & $55^{\circ} 06^{\prime}$ & 17.0 & 0.68 & 12.0 & 10 & 68 \\
\hline L64 & L64 & 554 & $63^{\circ} 07^{\prime}$ & $55^{\circ} 06^{\prime}$ & 13.0 & 0.57 & 12.0 & 14 & 61.5 \\
\hline L61 & L61 & 530 & $63^{\circ} 15^{\prime}$ & $55^{\circ} 52^{\prime}$ & 7.0 & 0.76 & 12.3 & 19 & 164.5 \\
\hline L58 & L58 & 513 & $62^{\circ} 44^{\prime}$ & $54^{\circ} 52^{\prime}$ & 4.0 & 0.97 & 12.3 & 18 & 152 \\
\hline L42 & L42 & 578 & $62^{\circ} 23^{\prime}$ & $54^{\circ} 49^{\prime}$ & 5.0 & 1.89 & 12.3 & 8 & 83 \\
\hline L41 & L41 & 587 & $62^{\circ} 21^{\prime}$ & $54^{\circ} 48^{\prime}$ & 14.0 & 1.00 & 12.2 & 13 & 82 \\
\hline L32 & L32 & 290 & $61^{\circ} 12^{\prime}$ & $54^{\circ} 28^{\prime}$ & 27.0 & 0.78 & 12.2 & 6 & 14.5 \\
\hline L29 & L29 & 306 & $61^{\circ} 09^{\prime}$ & $54^{\circ} 22^{\prime}$ & 14.0 & 0.78 & 12.1 & 13 & 49.5 \\
\hline L34 & L34 & 280 & $60^{\circ} 53^{\prime}$ & $54^{\circ} 18^{\prime}$ & 26.0 & 1.62 & 12.1 & 12 & 74.5 \\
\hline L28 & L28 & 285 & $61^{\circ} 08^{\prime}$ & $54^{\circ} 18^{\prime}$ & 3.0 & 1.65 & 12.0 & 16 & 94 \\
\hline L23 & L23 & 295 & $60^{\circ} 41^{\prime}$ & $53^{\circ} 38^{\prime}$ & 24.0 & 0.59 & 14.0 & 11 & 42 \\
\hline L22 & L22 & 136 & $60^{\circ} 45^{\prime}$ & $53^{\circ} 37^{\prime}$ & 14.0 & 0.70 & 14.0 & 15 & 56 \\
\hline L24 & L24 & 255 & $60^{\circ} 37^{\prime}$ & $53^{\circ} 36^{\prime}$ & 11.0 & 0.65 & 14.5 & 7 & 31 \\
\hline L10 & L10 & 221 & $56^{\circ} 52^{\prime}$ & $52^{\circ} 52^{\prime}$ & 2.0 & 1.30 & 13.5 & 18 & 57.5 \\
\hline L14 & L14 & 380 & $57^{\circ} 43^{\prime}$ & $52^{\circ} 22^{\prime}$ & 1.0 & 0.84 & 13.5 & 23 & 251 \\
\hline L20 & L20 & 371 & $57^{\circ} 33^{\prime}$ & $52^{\circ} 05^{\prime}$ & 1.0 & 1.30 & 13.5 & 25 & 196 \\
\hline L16 & L16 & 319 & $57^{\circ} 50^{\prime}$ & $52^{\circ} 05^{\prime}$ & 8.0 & 1.35 & 13.5 & 19 & 342.5 \\
\hline L17 & L17 & 319 & $57^{\circ} 52^{\prime}$ & $52^{\circ} 05^{\prime}$ & 6.0 & 0.54 & 13.5 & 20 & 315.5 \\
\hline L2 & L2 & 195 & $56^{\circ} 45^{\prime}$ & $51^{\circ} 35^{\prime}$ & 5.0 & 0.04 & 12.5 & 11 & 69 \\
\hline L3 & L3 & 43 & $57^{\circ} 14^{\prime}$ & $51^{\circ} 30^{\prime}$ & 23.0 & 1.05 & 12.5 & 12 & 72.5 \\
\hline L1 & $\mathrm{L} 1$ & 43 & $57^{\circ} 12^{\prime}$ & $51^{\circ} 27^{\prime}$ & 14.0 & 0.59 & 12.5 & 15 & 106 \\
\hline Black Lake & BLA & 34 & $64^{\circ} 22^{\prime}$ & $46^{\circ} 06^{\prime}$ & 6.0 & 0.18 & 18.4 & 19 & 174.5 \\
\hline Portey Pond & POR & 45 & $64^{\circ} 25^{\prime}$ & $45^{\circ} 21^{\prime}$ & 1.5 & 0.04 & 17.8 & 19 & 137.5 \\
\hline Leak Lake & LEA & 0 & $64^{\circ} 21^{\prime}$ & $45^{\circ} 25^{\prime}$ & 14.2 & 0.17 & 18.0 & 25 & 87.5 \\
\hline Ritchie Lake & RIT & 0 & $65^{\circ} 58^{\prime}$ & $45^{\circ} 25^{\prime}$ & 12.0 & 0.23 & 17.0 & 21 & 52 \\
\hline Long Lake & LON & 0 & $66^{\circ} 04^{\prime}$ & $45^{\circ} 19^{\prime}$ & 9.7 & 0.05 & 16.8 & 18 & 66 \\
\hline Joe Lake & JOE & 335 & $66^{\circ} 40^{\prime}$ & $46^{\circ} 45^{\prime}$ & 1.8 & 0.04 & 17.2 & 19 & 333.5 \\
\hline Killarneyl Lake & KIL & 75 & $66^{\circ} 38^{\prime}$ & $46^{\circ} 01^{\prime}$ & 9.8 & 0.11 & 19.0 & 20 & 413 \\
\hline Pine Ridge Pond & PIN & 85 & $67^{\circ} 06^{\prime}$ & $45^{\circ} 34^{\prime}$ & 5.6 & 0.01 & 18.5 & 12 & 131.5 \\
\hline
\end{tabular}




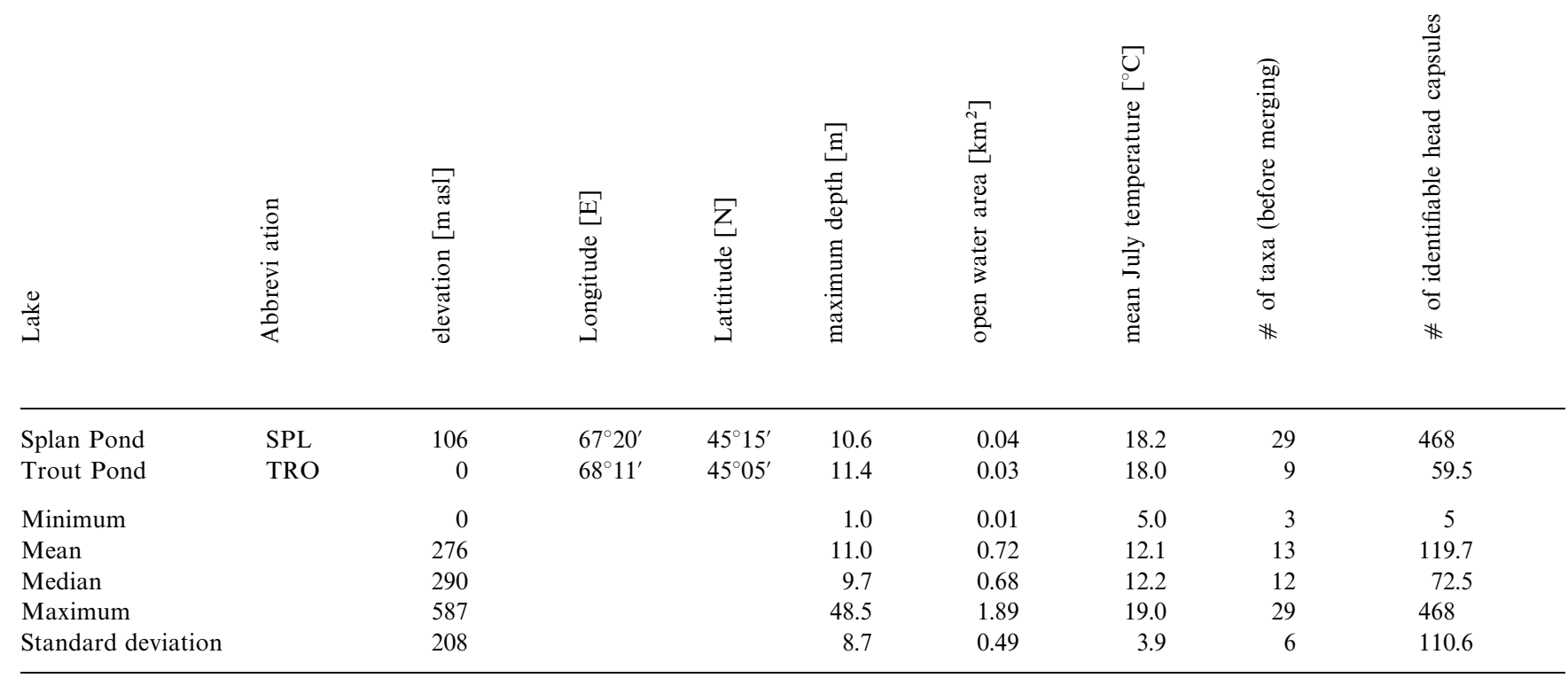

Table 2

Comparison of screened modern European and North American chironomid training sets, including performance of various chironomid-temperature regression models based upon apparent and jack-knifed statistics

\begin{tabular}{|c|c|c|c|}
\hline & $\begin{array}{l}\text { European } \\
\text { training set }\end{array}$ & $\begin{array}{l}\text { North American } \\
\text { training set }\end{array}$ & $\begin{array}{l}\text { Combined } \\
\text { training set }\end{array}$ \\
\hline Number of samples & 51 & 39 & 90 \\
\hline Min. July temperature $\left({ }^{\circ} \mathrm{C}\right)$ & 7.6 & 5.0 & 5.0 \\
\hline Max. July temperature $\left({ }^{\circ} \mathrm{C}\right)$ & 21.0 & 19.0 & 21.0 \\
\hline Median July temperature $\left({ }^{\circ} \mathrm{C}\right)$ & 15.0 & 12.2 & 12.5 \\
\hline Standard deviation $\left({ }^{\circ} \mathrm{C}\right)$ & 3.7 & 3.9 & 4.0 \\
\hline DCCA $\lambda_{1}$ & 0.275 & 0.349 & 0.301 \\
\hline$\lambda_{2}$ & 0.148 & 0.094 & 0.192 \\
\hline Species-environment correlation & 0.914 & 0.934 & 0.902 \\
\hline \multicolumn{4}{|l|}{ PLS } \\
\hline Number of PLS components & 1 & 3 & 1 \\
\hline Apparent $r^{2}$ & 0.871 & 0.958 & 0.822 \\
\hline Jack-knifed maximum bias & 3.194 & 1.545 & 4.916 \\
\hline \multicolumn{4}{|l|}{ WA (classical deshrinking) } \\
\hline Apparent $r^{2}$ & 0.786 & 0.885 & 0.805 \\
\hline$r_{\text {jack }}^{2}$ & 0.744 & 0.848 & 0.775 \\
\hline Apparent RMSE $\left({ }^{\circ} \mathrm{C}\right)$ & 1.941 & 1.443 & 1.977 \\
\hline $\mathrm{RMSE}_{\text {jack }}\left({ }^{\circ} \mathrm{C}\right)$ & 2.082 & 1.623 & 2.101 \\
\hline Jack-knifed mean bias & 0.049 & -0.015 & -0.001 \\
\hline Jack-knifed maximum bias & 3.055 & 2.341 & 3.926 \\
\hline \multicolumn{4}{|l|}{ WA-PLS } \\
\hline Number of WA-PLS components & 2 & 2 & 2 \\
\hline Apparent $r^{2}$ & 0.924 & 0.940 & 0.894 \\
\hline
\end{tabular}


Table 3

Taxon response models (Huisman et al., 1993) for all taxa with occurrences in at least $20 \%$ of the samples. Model A: Skewed unimodal relationship between taxon abundance and July temperature. Model B: symmetric unimodal relationship between taxon abundance and July temperature. Model C: monotonically increasing or decreasing sigmoidal relationship between taxon abundance and July temperature. Null model: no relationship between taxon abundance and July temperature: Taxon occurs in less than $20 \%$ of the samples

\begin{tabular}{llll}
\hline Taxon & North & European & Combined \\
& American & Training set & Training set \\
& & \\
& Training set & & \\
\hline
\end{tabular}

Tribe Pentaneurini

Procladius

Subtribe Tanytarsina

Stempellina

Stempellinella and Zavrelia

Pseudochironomus

Chironomus

Cladopelma

Cryptochironomus

Dicrotendipes

Endochironomus

Glyptotendipes

Lauterborniella and Zavreliella

Microtendipes

Pagastiella

Parachironomus

Polypedilum

Sergentia

Stictochironomus

Tribelos

Protanypus

Diamesa

Crictopus and Orthocladius

Corynoneura and Thienemanniella

Heterotanytarsus

Heterotrissocladius

Nanocladius

Paracladius

Parakiefferiella cf. bathophila

Other Parakiefferiella spp.

Psectrocladius

Zalutschia

Mesocricotopus thienemanii

Undifferentiated Orthocladiinae

$n$

Null model, no relationship

Model A, skewed unimodal relationship

Model B, symmetric unimodal relationship

Model C, sigmoidal relationship

\begin{tabular}{l} 
B \\
B \\
A \\
C \\
A \\
C \\
A \\
A \\
A \\
B \\
- \\
- \\
A \\
B \\
B \\
- \\
A \\
A \\
A \\
A \\
B \\
- \\
A \\
0 \\
B \\
C \\
- \\
- \\
A \\
- \\
C \\
C \\
C \\
0 \\
\hline
\end{tabular}

B

B

A

-

$-$

B $\quad$ B

B $\quad$ C

B

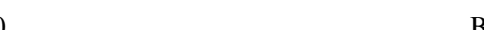

$\mathrm{B}-\mathrm{B}$

B

A

B $\quad$ C

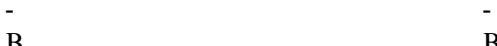

$\mathrm{B}-\mathrm{B}$

$--1$

B

A

B

0 10

$0-0$

-

A

C

0

0 - B

$-$

0

2125

6 - 4

$4-5$

10

1

point of view, cannot be distinguished to a lower taxonomic level. Such taxonomic units, however, very often lump several species with different environmental optima and tolerances. It is, therefore, intriguing to note how well the different quantitative inference models for chironomids generally perform. For example, harmonization resulted in the loss of 18 taxa in the European training set, but did not significantly change the predictive power of the new model in comparison to the original one.

\subsection{Optima, tolerances and WA-PLS regression coefficients}

Using WA, PLS, and WA-PLS regression we estimated optima, tolerances and WA-PLS regression coefficients (Beta coefficients) for the chironomid taxa on the two continents. This comparison involved a total of 34 taxa that occurred in both training sets. Twenty-three taxa $(68 \%)$ had lower optima, one $(3 \%)$ had the same optimum, and 10 taxa $(29 \%)$ had higher optima in the 


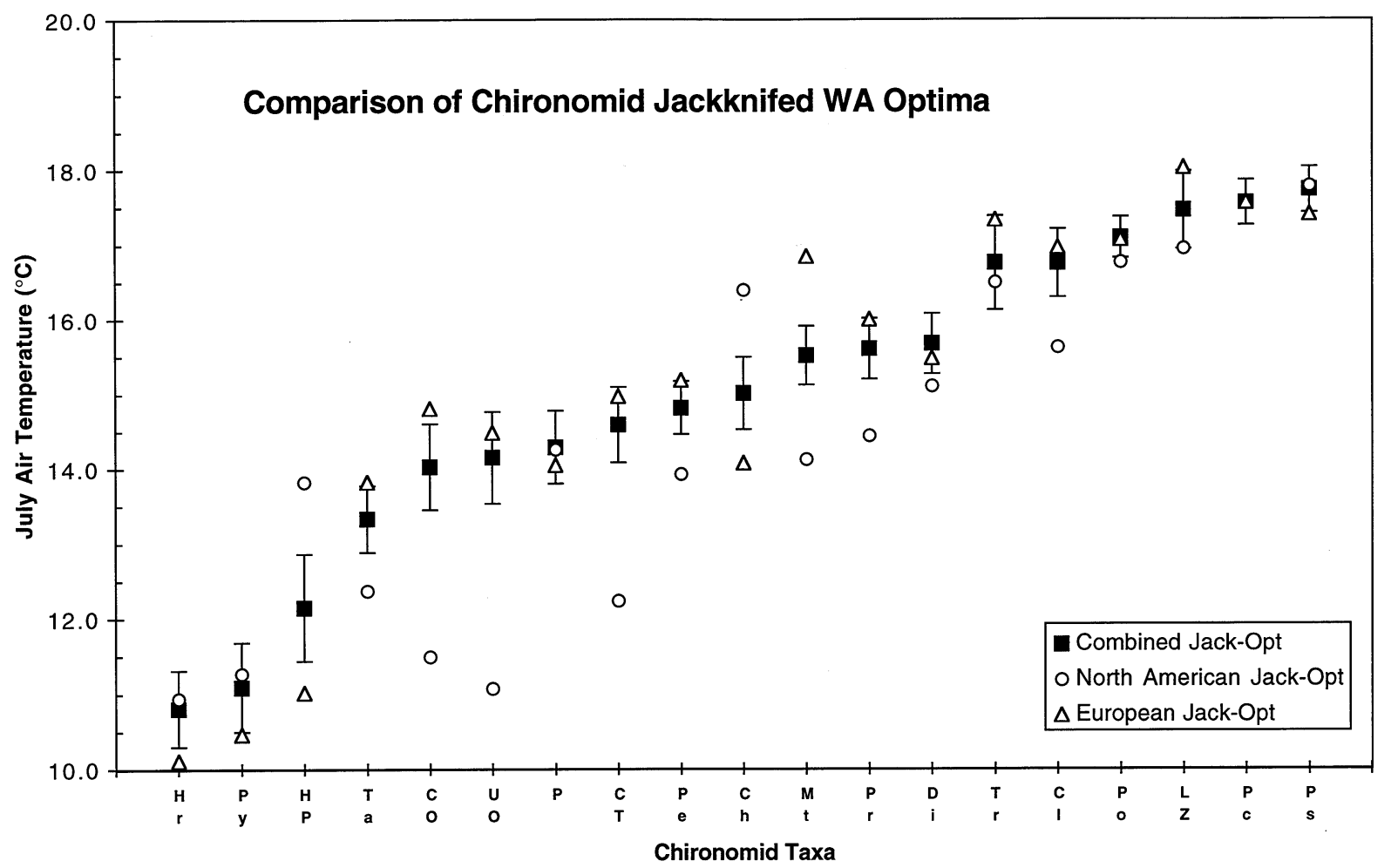

Fig. 1. Comparison of estimated WA July temperature optima for the North American, European, and combined training sets. Only taxa with a Hill's (1973) N2 > 5 in both training sets are shown. Chironomid taxa have been sorted from lowest to highest temperature optima in the combined data set. Jack-knifed optima, with bars spanning \pm 1 standard error of the optima. Taxon codes (alphabetically): Ch, Chironomus; Cl, Cladopelma; CO, Cricotopus/Orthocladius; CT, Corynoneura/Thienemanniella; Di, Dicrotendipes; HP, Cyphomella/Harnischia/Paracladopelma type; Hy, Heterotanytarsus; L/Z, Lauterborniella/Zavreliella; Mt, Microtendipes; P, Psectrocladius; Pc, Parachironomus; Pe, Tribe Pentaneurini; Po, Polypedilum; Pr, Procladius; Ps, Pseudochironomus; Py, Protanypus; Ta, Subtribe Tanytarsina; Tr, Tribelos; UO, Undifferentiated Orthocladiinae.

North American training set (Fig. 1). The largest differences in WA-optima occurred in taxa such as Potthastia $\left(5.5^{\circ} \mathrm{C}\right)$, Paracladius $\left(4.4^{\circ} \mathrm{C}\right)$, Diamesa $\left(3.5^{\circ} \mathrm{C}\right)$, Stempellina $\left(3.5^{\circ} \mathrm{C}\right)$, and the undifferentiated Orthocladiinae $\left(3.4^{\circ} \mathrm{C}\right)$. The large discrepancies in Diamesa optima can be attributed to the fact that it was recorded from only a single site in North America. Similarly, Potthastia was recorded from only a single European site. However, "undifferentiated Orthocladiinae" and other taxa were common in both training sets. To some extent, especially with regard to the "undifferentiated Orthocladiinae", these differences may reflect differences in chironomid taxonomy that could not be addressed fully by our taxonomic harmonization process.

Generally, the optima appear very similar, and are strongly correlated $(r=0.815)$ between the two training sets (Fig. 1). Overall, $22(65 \%)$ of the European jackknifed optima, and $16(47 \%)$ of the North American jack-knifed optima lie within one standard error of the mean jack-knifed optima, as calculated for the combined training set (Fig. 1).

For 31 taxa, temperature tolerance ranges could be calculated for both the North American and European data sets. The correlation $(r=0.565)$ between the European and North American tolerances was much lower than the correlation for optima. Eleven taxa $(35 \%)$ had narrower tolerances, one taxon had the same tolerance, and 19 taxa $(61 \%)$ had wider tolerances in the North American data set (Fig. 2). Fifteen (48\%) of the European jack-knifed tolerances, and $16(52 \%)$ of the North American jack-knifed tolerances lay within one standard error of the mean jack-knifed optima, as calculated for the combined training set (Fig. 2).

We also compared the regression (Beta) coefficients for the best WA-PLS and PLS models. This revealed correlation coefficients of $0.632,0.736$ and 0.156 between WA-PLS (two component), PLS (one component), and PLS (three component) regression coefficients, respectively.

\subsection{Using one training set to predict temperatures at the other sites}

Applying the North American two-component WAPLS inference model to predict mean July temperatures at the European sites yielded sample specific standard 


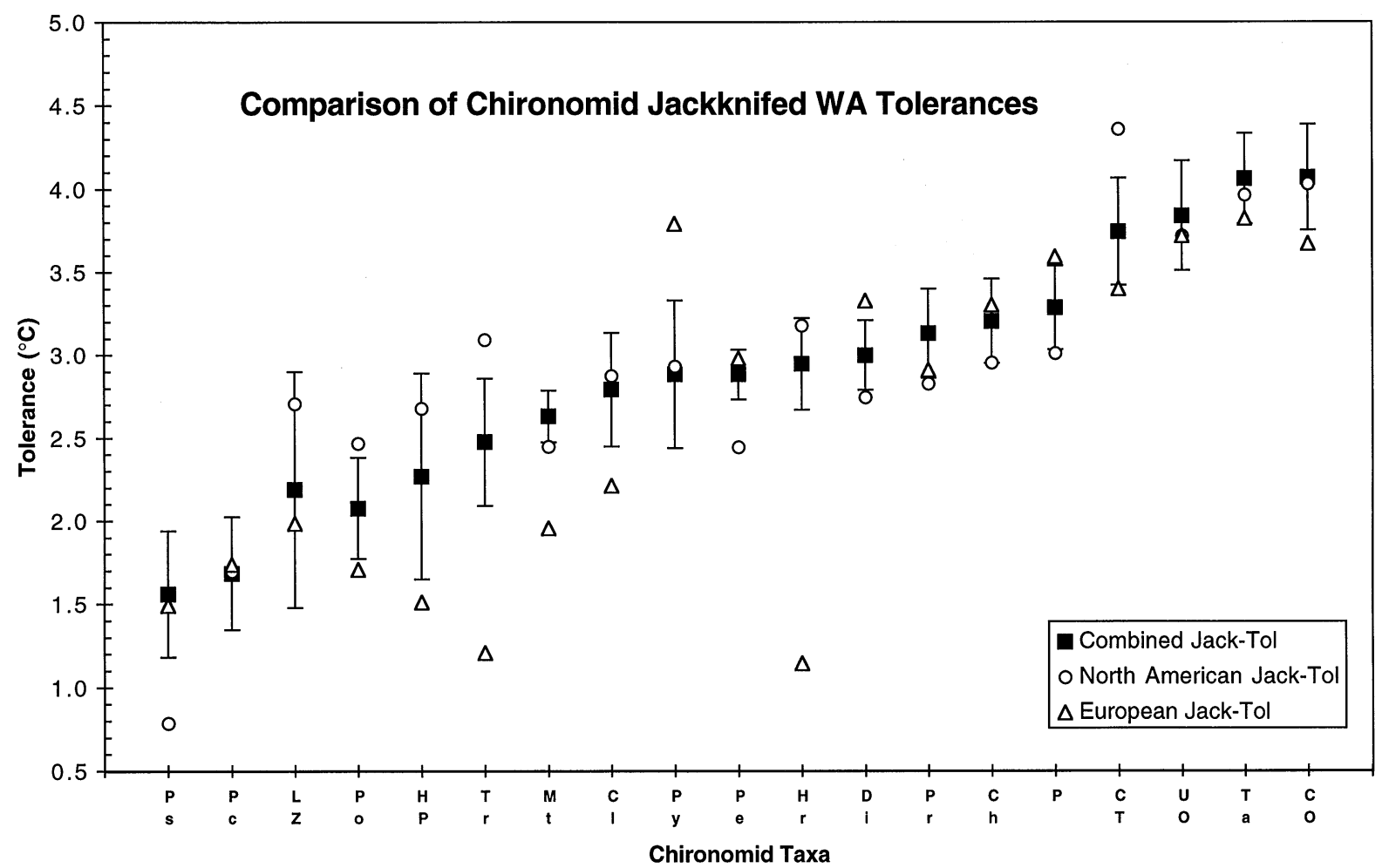

Fig. 2. Comparison of estimated WA tolerances for the North American, European, and combined training sets. Only taxa with a Hill's (1973) N2 $>5$ in both training sets are shown. Chironomid taxa have been sorted from lowest to highest July temperature tolerances in the combined data set. Jack-knifed tolerances, with bars spanning \pm 1 standard error of the tolerances. For taxon codes see caption for Fig. 1.

error ranges which encompassed the 'observed' temperatures for $78.4 \%$ of the sites (Fig. 3). The correlation coefficient between model predicted and observed July temperatures is 0.767 and the WA-PLS model-predictions explained $58.8 \%$ of the variance in the European July temperature data (see Table 4).

Significant deviations occurred at the lower end of the temperature gradient between 8 and $13^{\circ} \mathrm{C}$, where the inference model overestimated the temperatures. At the high end of the gradient, the model underestimated the mean July temperatures for two sites from the southern Alpine foreland (Fig. 3). This phenomenon has also been observed for other organisms in connection with lakes from this so-called insubric climate region (warm, precipitation-rich summers, mild winters, see Lotter et al., 1997). It is, therefore, likely that the warmer climatic conditions prevailing on the southern side of the Alps create physical properties in these lakes that are not comparable to the ones prevailing in temperate lakes on the northern side of the Alps. A separate training set focussing on lakes on the southern slope of the Alps as well as the Mediterranean region might help solve this problem.

Using the European two-component WA-PLS inference model to infer present-day temperatures at North
American sites, we noted $71.8 \%$ of the observed mean July temperatures lay within the range defined by the site-specific errors (Fig. 4). Temperatures at the lower end of the gradient, around $5^{\circ} \mathrm{C}$, tended to be overestimated. Observations lying outside the site-specific errors were scattered in the middle and upper part of the temperature gradient. There is a higher correlation $(r=0.849$, see Table 4$)$ between model-predicted and observed July temperatures and a larger portion of the variance $(72 \%)$ was explained by the European model when applied to the North American data set.

However, although the two-component WA-PLS models performed consistently superior to all other chironomid-temperature models, this result was not corroborated by the "inter-continental cross-validation" (Table 4). Our calculations indicate that the North American one-component PLS model provided much better temperature estimates $\left(r^{2}=0.770\right.$, RMSE $=$ $1.85^{\circ} \mathrm{C}$ ) for European sites than North American WA or WA-PLS models. The European one-component WAPLS model which is equivalent to a WA model with inverse deshrinking provided better estimates $\left(r^{2}=0.778, \mathrm{RMSE}=1.91^{\circ} \mathrm{C}\right)$ of temperatures at North American lakes, than all other European models. This cross-validation shows that the performance of a model 


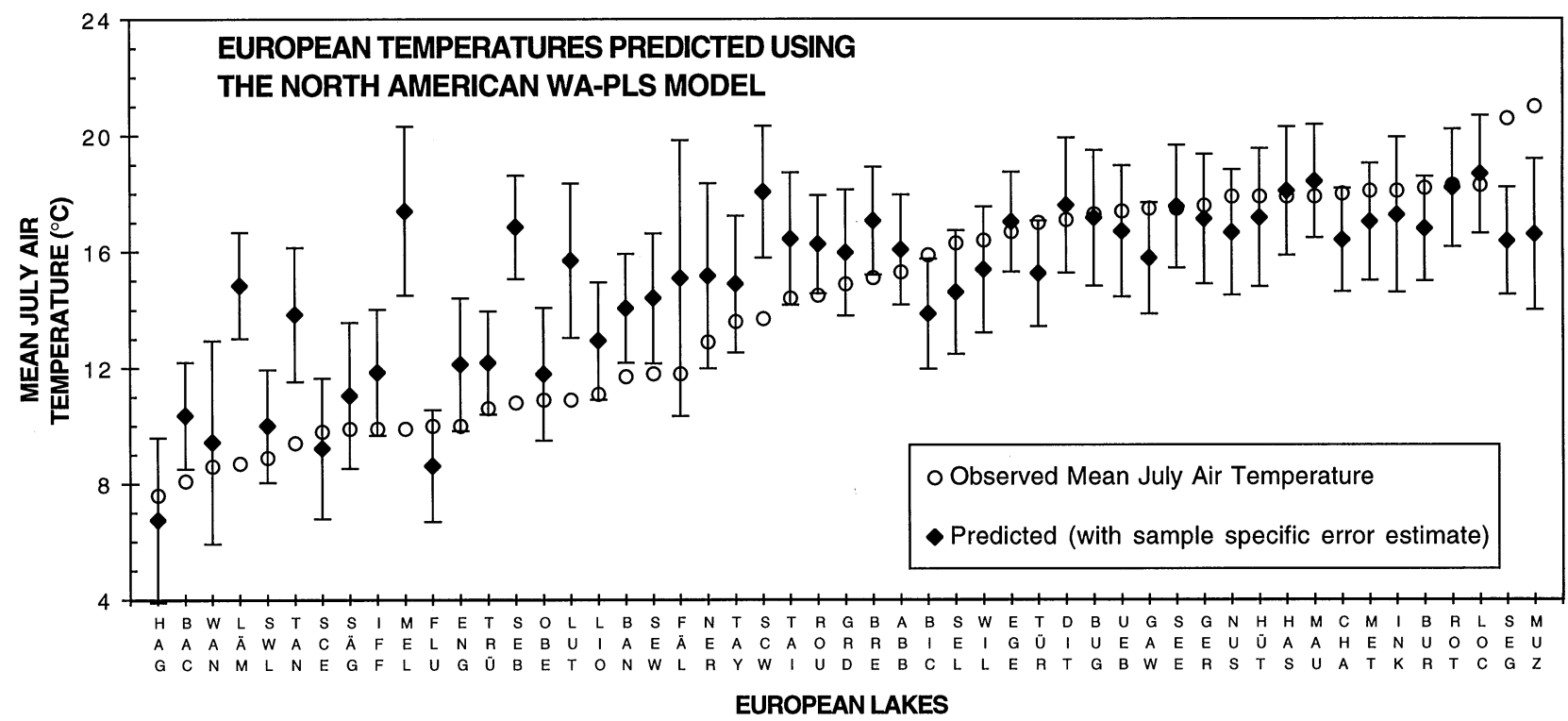

Fig. 3. Prediction of mean July temperature for the European sites using the North American two-component WA-PLS inference model. The sites are arranged according to their mean July air temperatures. Open dots signify the measured mean July air temperatures, whereas the filled diamonds show the chironomid-inferred mean July temperatures including the sample-specific error of prediction as assessed by 10,000 simulations. For site codes see Table 1a.

Table 4

Comparison of various chironomid-temperature regression models, assessed on their ability to estimate temperatures at lakes on the other continent

\begin{tabular}{llll}
$\begin{array}{l}\text { North American } \\
\text { model estimating }\end{array}$ & $\begin{array}{l}\text { European model } \\
\text { estimating }\end{array}$ & $\begin{array}{l}\text { Combined model } \\
\text { estimating }\end{array}$ & $\begin{array}{l}\text { Combined model } \\
\text { estimating }\end{array}$ \\
$\begin{array}{l}\text { European } \\
\text { temperatures }\end{array}$ & $\begin{array}{l}\text { North American } \\
\text { temperatures }\end{array}$ & $\begin{array}{l}\text { European } \\
\text { temperatures }\end{array}$ & $\begin{array}{l}\text { North American } \\
\text { temperatures }\end{array}$ \\
\hline
\end{tabular}

\begin{tabular}{|c|c|c|c|c|c|}
\hline Number of observations & & 51 & 39 & 51 & 39 \\
\hline \multirow[t]{3}{*}{ WA (Classical deshrinking) } & $r$ & 0.748 & 0.882 & 0.872 & 0.913 \\
\hline & $r^{2}$ & 0.559 & 0.778 & 0.761 & 0.834 \\
\hline & RMSE & 2.71 & 2.01 & 2.01 & 1.93 \\
\hline \multirow[t]{3}{*}{ WA-PLS (2 components) } & $r$ & 0.767 & 0.849 & 0.943 & 0.946 \\
\hline & $r^{2}$ & 0.588 & 0.721 & 0.889 & 0.896 \\
\hline & RMSE & 2.52 & 2.27 & 1.30 & 1.32 \\
\hline \multirow[t]{3}{*}{ PLS (1 component) } & $r$ & 0.878 & 0.864 & 0.902 & 0.900 \\
\hline & $r^{2}$ & 0.770 & 0.746 & 0.813 & 0.810 \\
\hline & RMSE & 1.85 & 2.19 & 1.65 & 1.75 \\
\hline \multirow[t]{3}{*}{ MAT (mean of 7 analogues) } & $r$ & 0.786 & 0.814 & 0.823 & 0.924 \\
\hline & $r^{2}$ & 0.617 & 0.662 & 0.677 & 0.853 \\
\hline & RMSE & 2.46 & 3.02 & 2.19 & 1.78 \\
\hline
\end{tabular}

(see, e.g. Birks, 1995) cannot be accurately assessed on the basis of the highest $r_{\text {jack }}^{2}$ and the lowest RMSEP jack $_{\text {only }}$ (see Table 2). Moreover, the comparison also shows that the combined inter-regional model consistently performs better and explains more variance in the regional data sets than each regional data set alone (Table 4).

\subsection{Modern analogues}

The best models for inferring temperatures based on the modern analogue technique were selected on the basis of the highest $r^{2}$ and lowest RMSE. The best European model was based on a mean of the 9 closest 


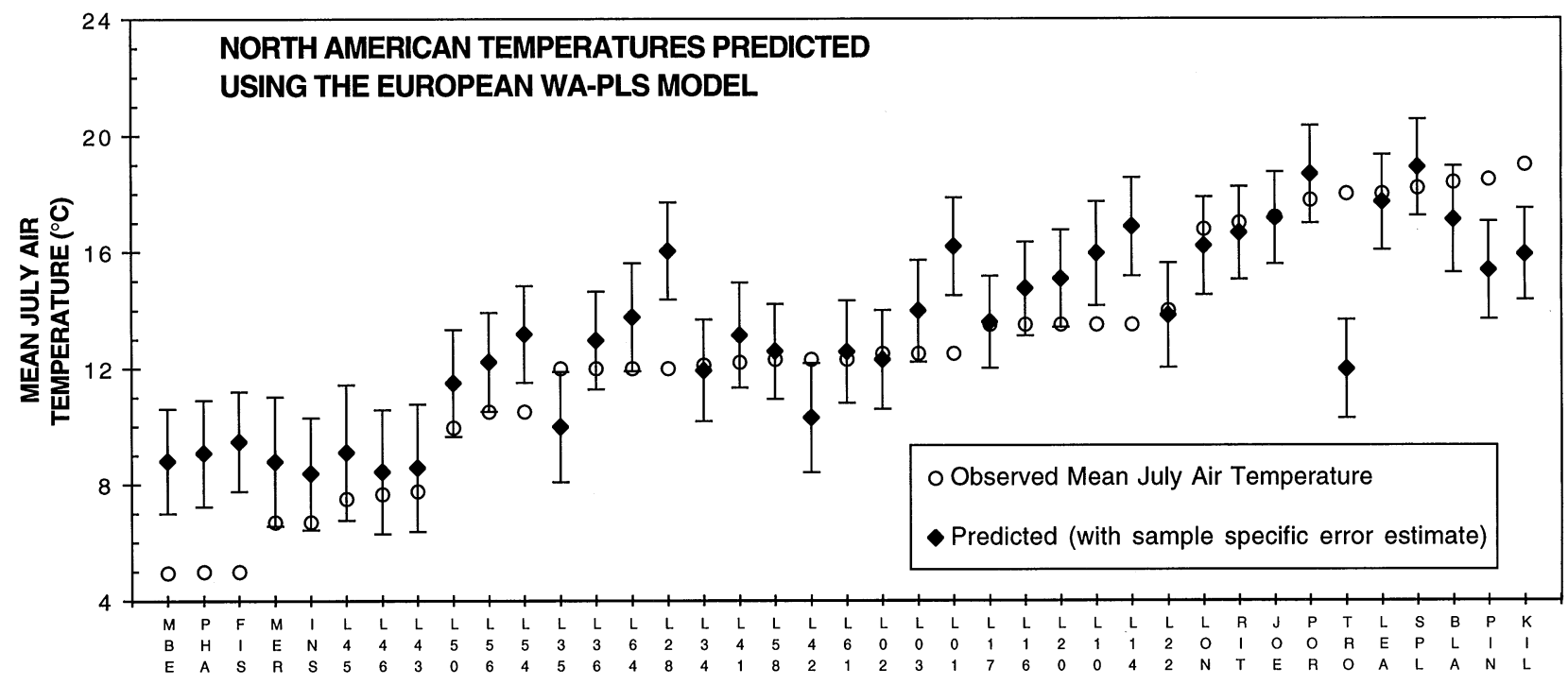

NORTH AMERICAN LAKES

Fig. 4. Prediction of mean July temperature for the North American sites using the European two-component WA-PLS inference model. The sites are arranged according to their latitude. Open dots signify the measured mean July air temperatures, whereas the filled diamonds show the chironomidinferred mean July temperatures including the sample specific error of prediction as assessed by 10,000 simulations. For site codes see Table $1 \mathrm{~b}$.

analogues $\left(r^{2}=0.691 ; \operatorname{RMSE}=2.14^{\circ} \mathrm{C}\right)$. The best North American and combined models were based on a mean of the 3 closest analogues (North America: $r^{2}=0.930$, $\operatorname{RMSE}=1.08^{\circ} \mathrm{C} ; \quad$ Combined: $\quad r^{2}=0.782, \quad \mathrm{RMSE}=$ $\left.1.90^{\circ} \mathrm{C}\right)$.

When used as analogues to predict European July temperatures, the North American training set gave a lower RMSE $\left(2.46^{\circ} \mathrm{C}\right)$ and a lower $r^{2}(0.617)$, than when the European training set was used to provide analogues to infer North American temperatures $\left(\mathrm{RMSE}=3.02^{\circ} \mathrm{C}\right.$; $r^{2}=0.662$ ).

For the 43 North American sites neither close nor good analogues existed in the European training set (Fig. 5a). The European modern analogue model tended to overestimate the real temperatures at North American sites. Twenty observations $(46.5 \%)$ lay within the range of the RMSE (Fig. 5b). For the 58 European sites there were no close analogues and only 3 good North American analogues (Fig. 6a): BUR and L17; SEL and L17; FLU and Middle Beschel Lake. The modern analogue model predicted only 21 sites $(36 \%)$ within the limit of the RMSE (Fig. 6b). There was a general tendency for the model to underestimate the real temperatures. All three sites that had good analogues, according to the 5th percentile rule (Birks et al., 1990; Birks, 1995; Jones and Juggins, 1995), had chironomidinferred July temperatures well outside the limits suggested by the RMSE, whereas the sites with good correspondence between observed and predicted temperatures had, in many cases, large Chi-squared distances (i.e. poor analogues).
The fact that despite a poor analogue situation, the models were able to reliably predict the actual temperatures, implies that temperature and other environmental reconstructions may be used in no-analogue situations, such as the Lateglacial period.

\subsection{Quantitative reconstruction}

We applied the different inference models to the Lateglacial chironomid stratigraphies of Splan Pond, in Atlantic Canada (Walker et al., 1991b) and Whitrig Bog in Scotland (Brooks et al., 1997a,b) to compare the performance of the different training sets, as well as the different inference models. These stratigraphies include the time between deglaciation and the Preboreal chronozone (i.e. between ca. 12,000 and 9000 conventional radiocarbon years BP). This period was marked by the Younger Dryas, a climatic cooling that took place between ca. 11,000 and $10,000{ }^{14} \mathrm{C}$ years BP (e.g. Ammann and Lotter, 1989; Björck et al., 1996). This cooling has been recorded in continental records on both sides of the Atlantic (e.g. Peteet, 1992) as well as in different ice-core records (e.g. Jouzel et al., 1994; Johnsen et al., 1995). Several shorter climatic oscillations have also been demonstrated in continental oxygen isotope and palynological records (see e.g. Lotter et al., 1992; Levesque et al., 1993). We concentrated our comparison on this well-established and well-defined high-amplitude Lateglacial climatic oscillation.

Because of the predominantly unimodal taxon response models (see Table 3) we have applied unimodal-based 


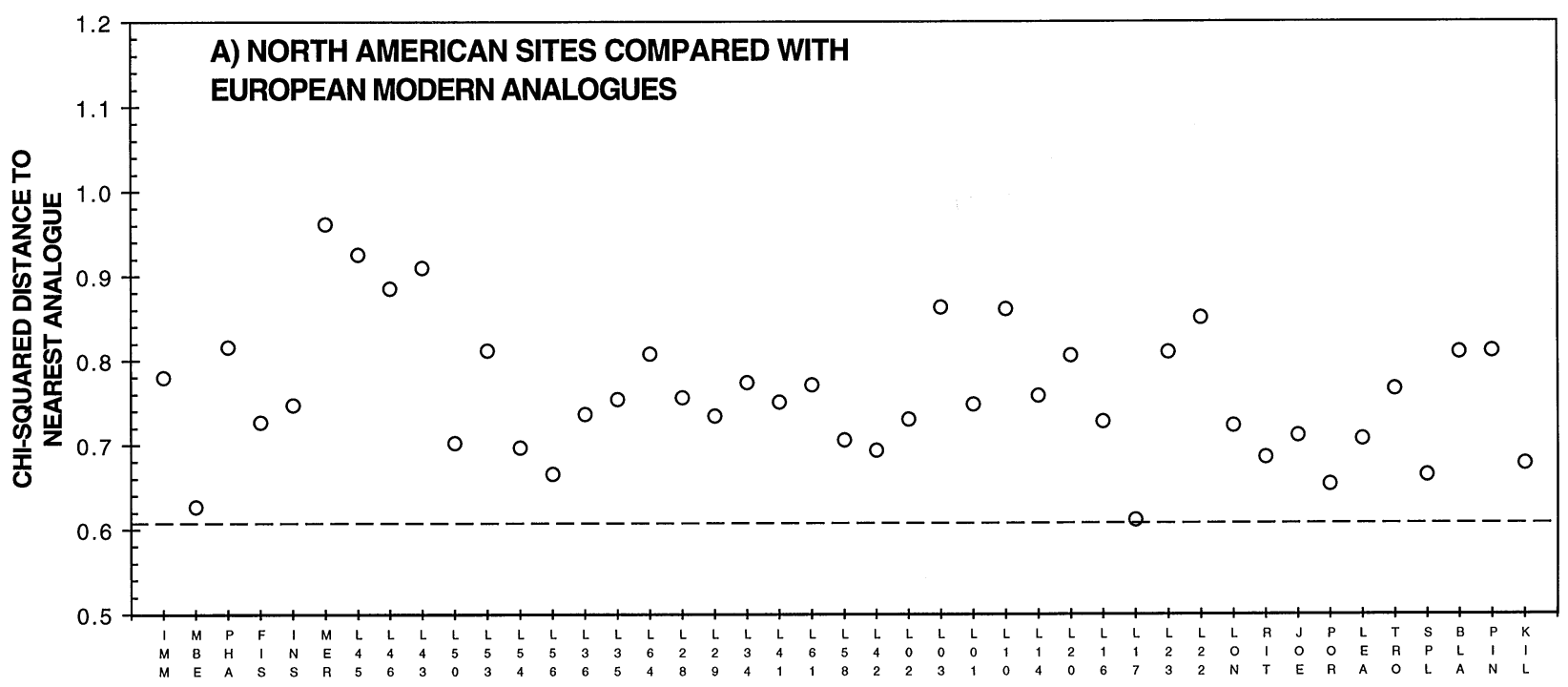

(a)

CANADIAN LAKES

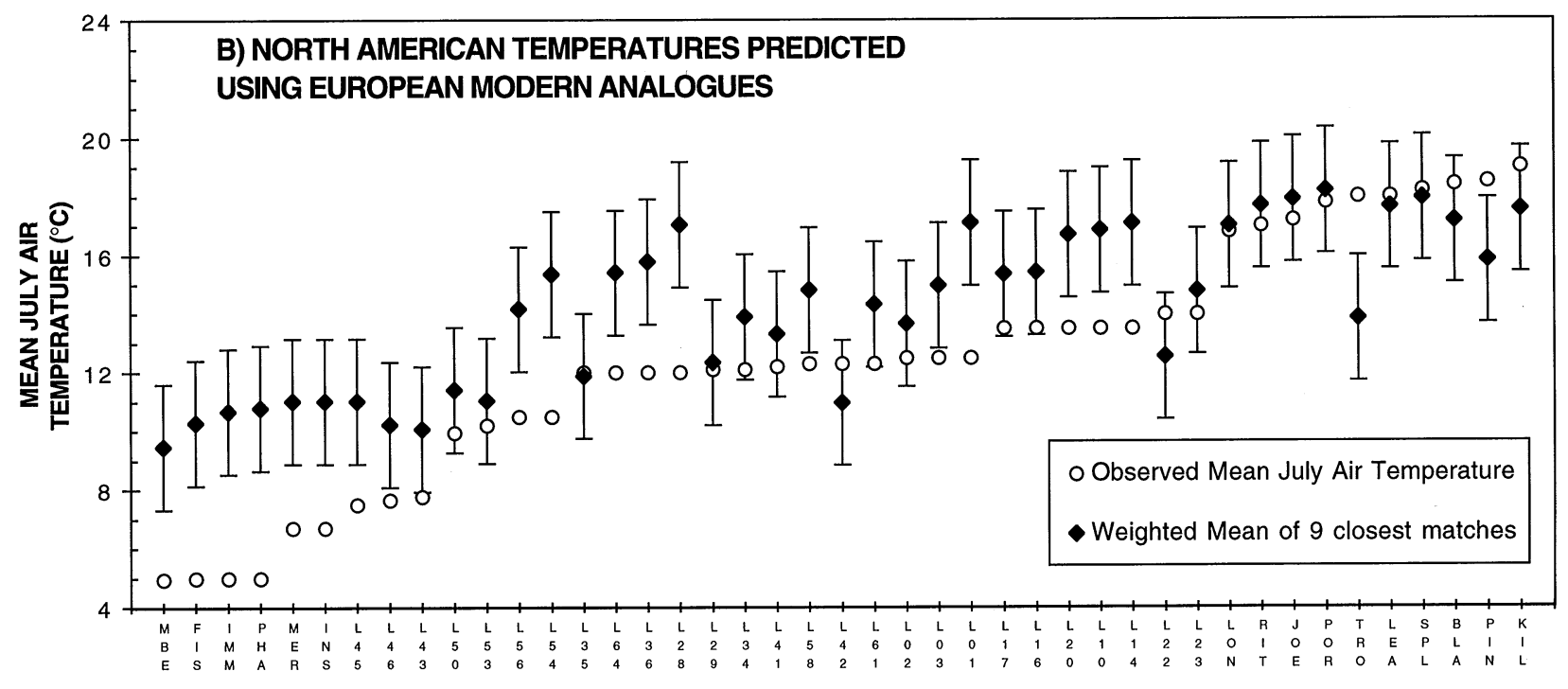

(b)

CANADIAN LAKES

Fig. 5 (a) Chi-squared distances between the 43 North American chironomid assemblages and their closest European analogue. Values below the dashed line (5th percentile) indicate good analogues. (b) Mean July air temperatures predicted (black diamonds) by a modern chironomid analogue model using the weighted mean of the 9 closest matches in the European data set and observed mean July temperatures at 43 North American sites. The sites are ordered according to increasing mean July air temperature (see Table $1 \mathrm{~b})$. The error bars represent the RMSE $\left(= \pm 2.136^{\circ} \mathrm{C}\right)$.

inference models such as WA and WA-PLS to the fossil data. However, since $5-22 \%$ of the prominent taxa show a sigmoidal relationship with July temperature, we have also applied a linear-based PLS inference model. Moreover, we estimated past July temperatures using MAT. For reasons of comparison we have applied all three models to both fossil data sets. The principal focus of this comparison should, however, be the comparison of reconstructions derived from each regional data set with the reconstruction derived from the combined data set.
With WA, WA-PLS and PLS, the European training set generally inferred lower July temperatures at Splan Pond than the North American training set (Fig. 7). When based on the combined data set, the July temperature inferences commonly lay between the European and North American estimates. This pattern was not so apparent in the Whitrig Bog reconstructions (Fig. 8). At Whitrig Bog, the European WA model tended to infer lower July temperatures than the North American WA model through the Younger Dryas, but the North American PLS model inferred lower temperatures than the 


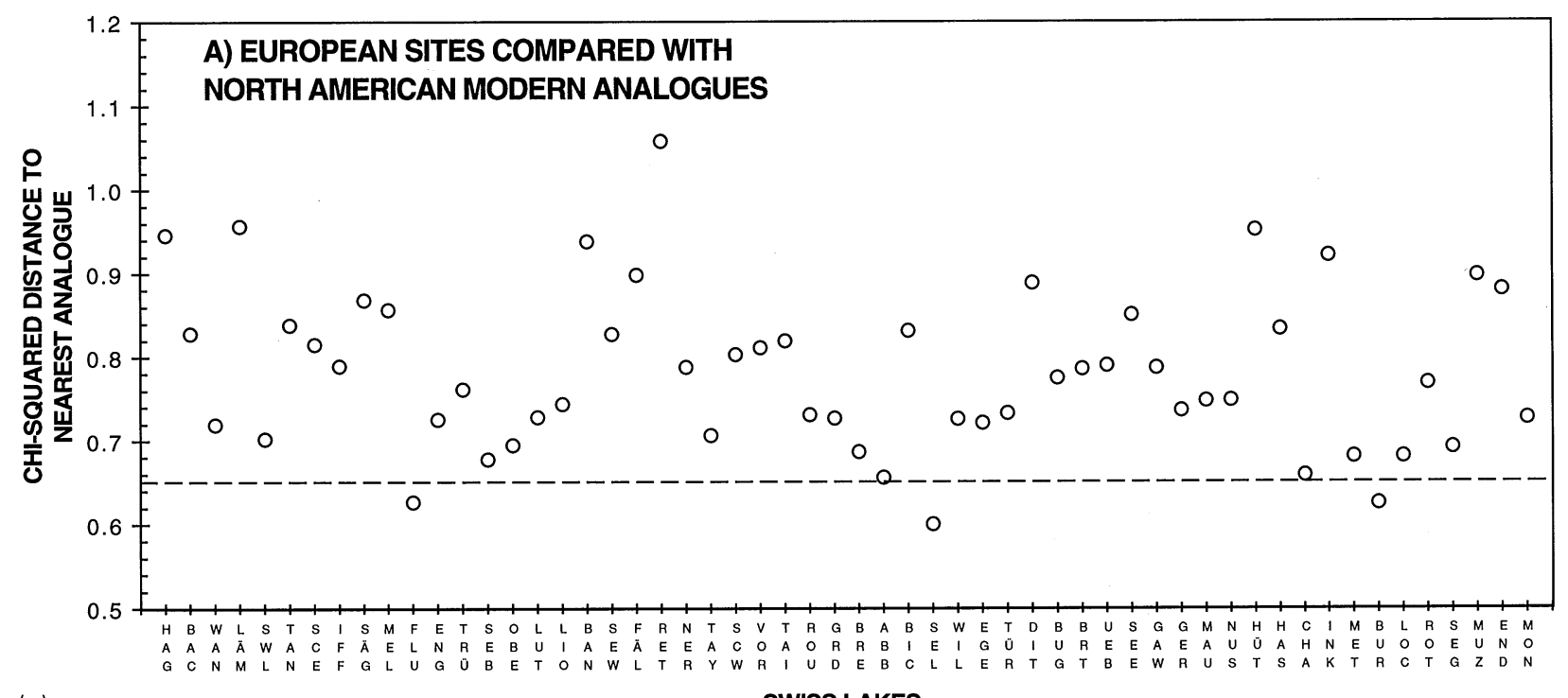

(a)

SWISS LAKES

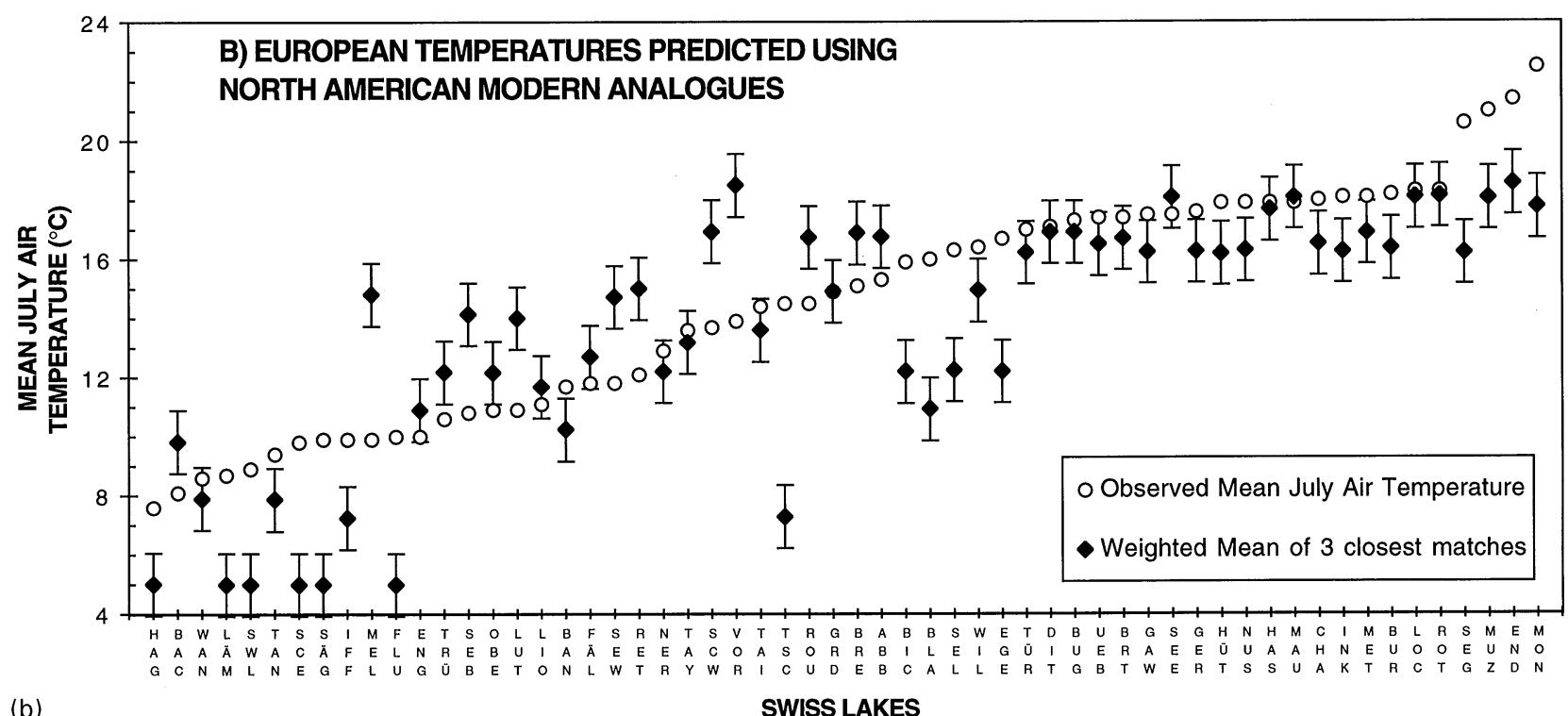

Fig. 6 (a) Chi-squared distances between the 58 European chironomid assemblages and their closest North American analogue. Values below the dashed line (5th percentile) indicate good analogues. (b) Mean July air temperatures predicted (black diamonds) by a modern chironomid analogue model using the weighted mean of the 3 closest matches in the North American data set and observed mean July temperatures at 58 European sites. The sites are ordered according to increasing mean July air temperature (see Table 1a). The error bars represent the RMSE $\left(= \pm 1.062^{\circ} \mathrm{C}\right)$.

European PLS model throughout most of the Lateglacial period.

The MAT approach produced the smoothest July temperature curves for Splan Pond (Fig. 7). The MAT reconstructions based on the North American and combined training sets were virtually identical because the method chose the same sites as closest analogues. The European data set provided one good modern analogue (CHA) for the sample at $190 \mathrm{~cm}$, whereas the North American data set provided two close modern analogues (Ritchie, L35) for the samples at 95 and $105 \mathrm{~cm}$ and four good modern analogues (L64, L35, L17, Killarney) for the samples at $125,145,183$, and $190 \mathrm{~cm}$. The same two close modern analogues and eight good modern analogues (twice L64, L35, L17, Leak, Portrey, CHA, MET) were identified when we used the combined training set. The closest modern samples (i.e., the samples with the lowest Chi-squared distance) remain the same, except for the sample at $190 \mathrm{~cm}$ (CHA instead of Killarney), but the cut-off level for good modern analogues increased from $<0.635$ to 0.665 when these two training sets were combined. As a result, more good modern analogues were apparent with the combined training set. 

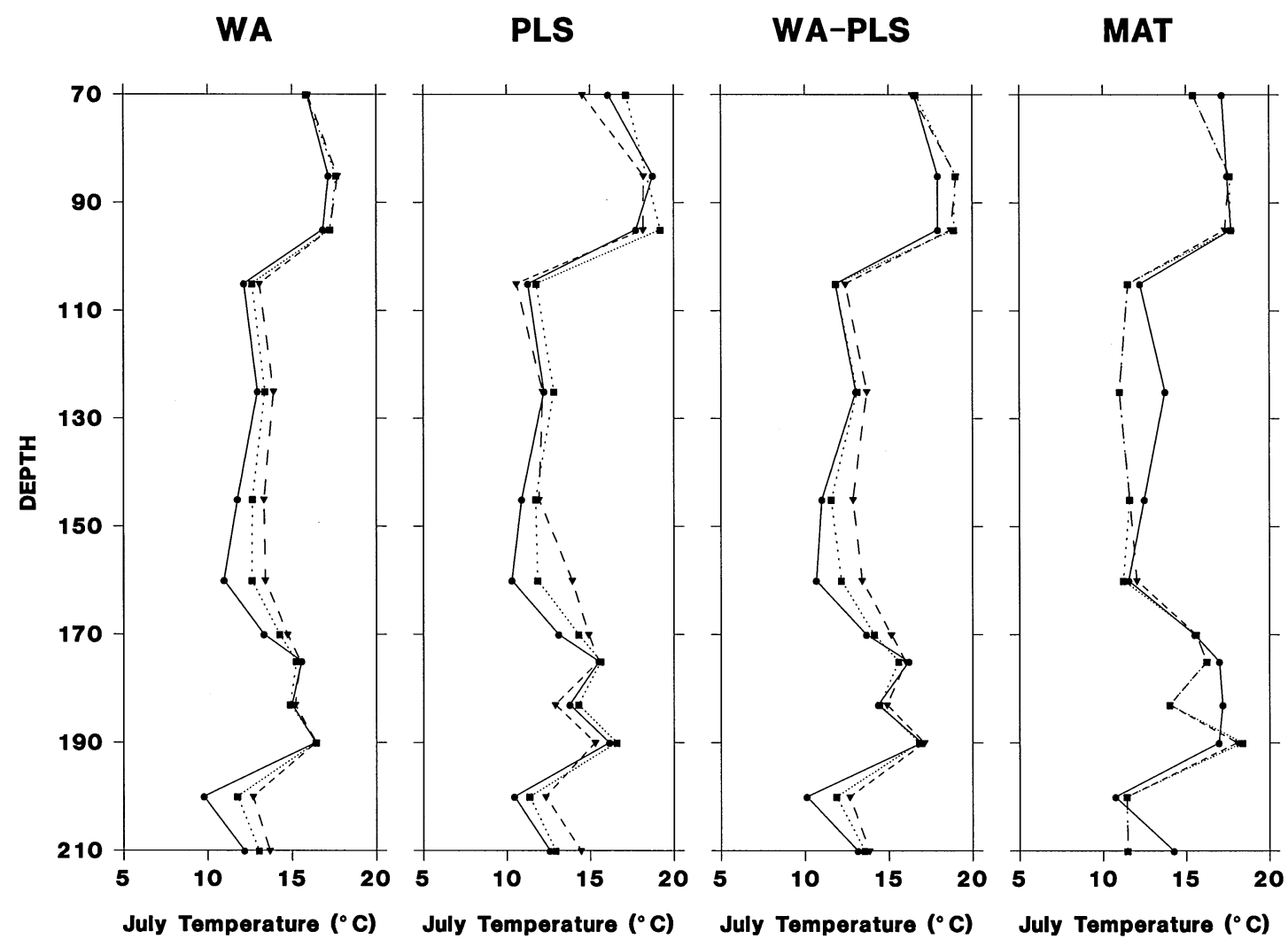

Fig. 7. Comparison of the chironomid-inferred July temperatures for the Lateglacial of Splan Pond using different quantitative inference models: Weighted Averaging with classical deshrinking (WA), Partial Least Squares (PLS), Weighted Averaging Partial Least Squares (WA-PLS), and Modern Analogue Technique (MAT) using Chi-squared distance as dissimilarity coefficient. Each model has been run with the European (dots, solid line), North American (triangles, dashed line), and combined training set (squares, dotted line).

Depending on which data set is used, different cut-off levels will result (see, e.g. Figs. 5 and 6). This highlights one problem inherent to the modern analogue approach. The method is sensitive to the presence or absence of strong taxa. The choice of close and good analogues using percentiles as cut-off levels is based on ecological and palaeoecological arguments rather than on a statistical basis. As an alternative, it may therefore be sensible to check for missing taxa in the modern training set or for taxa with low occurrences common in the modern and the fossil data set when assessing and evaluating the reliability of inference models (see Birks, in press).

The three MAT reconstructions for Whitrig Bog all appear very similar (Fig. 8), except for the anomalously low values inferred by the Canadian and combined data sets at $106 \mathrm{~cm}$. Fish Lake, in the Canadian high arctic, was identified as the only site providing a good analogue for this sample. In applying the European model, only four samples were identified as having close modern analogues, with nine additional samples having good modern analogues. Similarly, using the North American model, eight Whitrig Bog samples had close analogues, and 13 additional samples had good analogues.
When we combined the training sets, $19(25 \%)$ of the Whitrig Bog samples were identified as having close modern analogues. Good modern analogues were apparent for an additional $21(28 \%)$ samples. In total, 29 close analogues and 63 good analogues were identified with the combined training set. North American sites contributed $52 \%$ of the close analogues, but European sites provided $65 \%$ of the good analogues. In general, North American sites provided better analogues for Younger Dryas samples, but European sites provided better analogues for the Allerød period. This may well be related to the fact, that the North American training set includes arctic/subarctic sites with lower temperatures than the European training set (see Tables 1 and 2). Therefore, this training set may provide better modern analogues for past low-temperature assemblages. This is consistent with the observation that Europe currently has no high arctic landscapes.

Because it was not possible to decide which inference model was the most appropriate for the fossil data sets we have used a combined reconstruction, utilizing the results of the four different inference models (Figs. 9 and 10). All four models gave slightly different reconstructions 

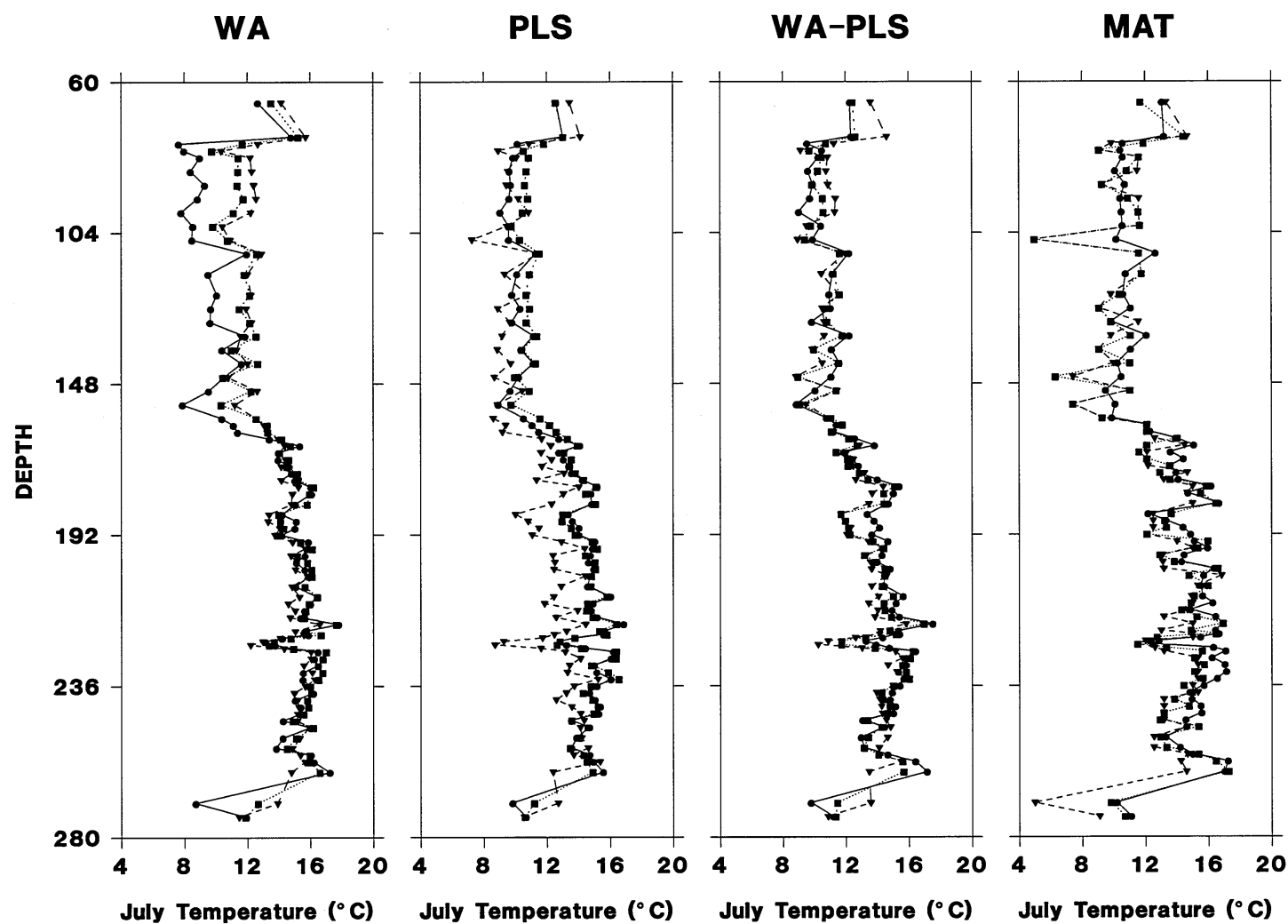

Fig. 8. Comparison of the chironomid-inferred July temperatures for the Lateglacial of Whitrig Bog using different quantitative inference models: Weighted Averaging with classical deshrinking (WA), Partial Least Squares (PLS), Weighted Averaging Partial Least Squares (WA-PLS), and Modern Analogue Technique (MAT) using Chi-squared distance as dissimilarity coefficient. Each model has been run with the European (dots, solid line), North American (triangles, dashed line), and combined training set (squares, dotted line).

because they emphasise different features of the data. Given RMSEP of between 1.5 and $2{ }^{\circ} \mathrm{C}$ (Table 2) most of the inferred July temperatures lay within this range. The smoothed curves presented in Figs. 9 and 10, therefore, represent estimates of past temperature change that are encompassed by these inherent errors. Applying uniquely the inference model with the best performance (i.e. highest $r^{2}$ and lowest RMSEP) to the fossil data would ignore the cross-validation results (Table 4 ) as well as the different proportions of unimodal and sigmoidal taxon-environment response models (Table 3).

Each training set gave a curve of similar shape for the Splan Pond and Whitrig Bog data sets. The European training set, however, inferred a more rapid temperature change than the other data sets for the Younger Dryas cooling, but not for the Preboreal warming. At Splan Pond, this feature is mainly due to the fact that the European models infer a stronger cooling already at $170 \mathrm{~cm}$, whereas the other models suggest that cooling only began at $160 \mathrm{~cm}$ of sediment depth. This holds true for all models applied to the Splan Pond data (Figs. 7 and 9), except the MAT model. With the MAT models, the temperatures inferred from all three training sets suggest a gradual cooling at the onset of the Younger Dryas.
For Whitrig Bog, the European WA model infers the most rapid temperature changes, at both the beginning and end of the Younger Dryas, but the North American PLS model infers more rapid temperature changes than the European PLS model (Fig. 8). With close interval sampling at Whitrig Bog, several brief climatic oscillations, perhaps correlative with the Older Dryas, Aegelsee and/or Amphi-Atlantic (Killarney and Gerzensee) Oscillations (Brooks et al., 1997b), are revealed within the Lateglacial interstadial. (Figs. 8 and 10).

Both sites and the reconstructions with all different models suggest a gradual decrease in summer temperatures at the onset of the Younger Dryas, whereas the warming at its end is more abrupt. These results are in good agreement with ice-core data that also suggest a gradual cooling at the onset of the Younger Dryas stadial and a rapid warming at the transition to the Holocene (e.g. Dansgaard et al., 1989; Taylor et al., 1993). The inferred cooling at the Allerød-Younger Dryas transition seems to be more pronounced at Whitrig Bog. Depending on the modern training set applied to the fossil chironomid data the temperature decrease at the Scottish site ranges between 4 and $5.5^{\circ} \mathrm{C}$, whereas at Splan Pond a cooling of $2.5-4.5^{\circ} \mathrm{C}$ in July temperature 
European Set

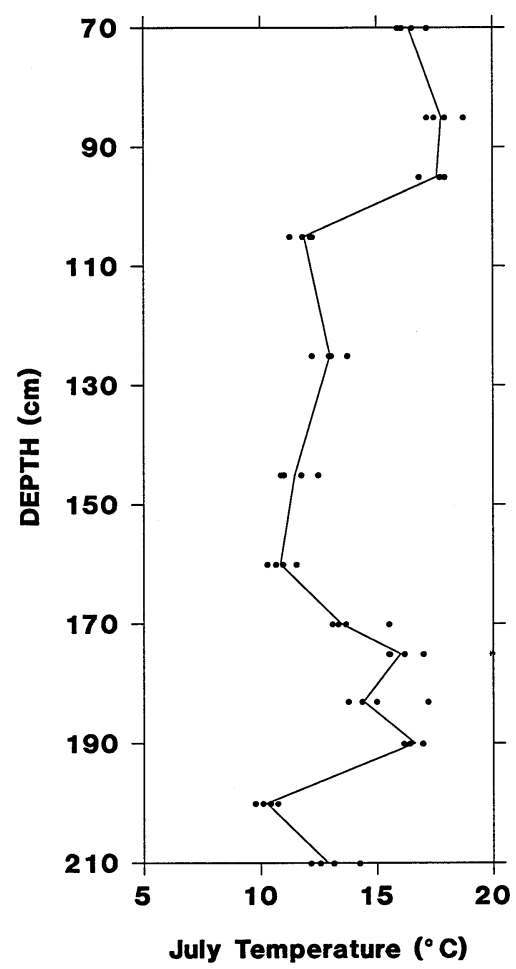

North American Set

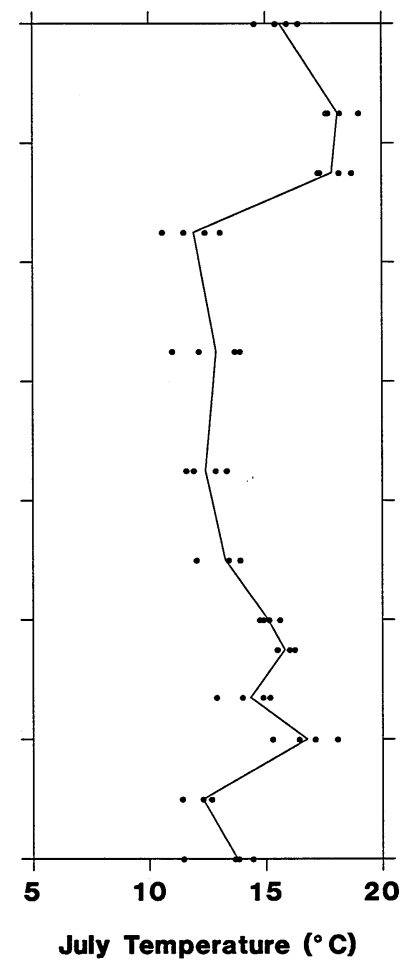

Combined Set

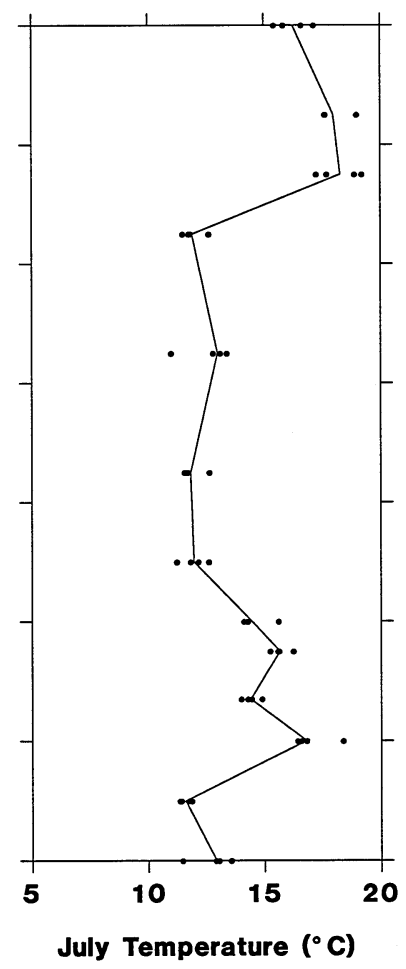

Fig. 9. Comparison of the chironomid inferred July temperature for the Lateglacial of Splan Pond. For each training set a combined reconstruction has been carried out based on the inferences of the four models shown in Fig. 7. A LOWESS smoother was fitted through the data points.

was inferred. The warming at the Younger Dryas-Preboreal transition seems to be stronger at the North American site. At Splan Pond an increase in July temperatures between 6 and $6.5^{\circ} \mathrm{C}$ was inferred, whereas the European site suggested a warming in the range of $2.5-3^{\circ} \mathrm{C}$. There are only very few studies using comparable quantitative climate reconstructions as of yet. Pollen and cladoceran-based inference models at Gerzensee on the Swiss Plateau reconstructed a gradual decrease in mean summer temperature of between 2 and $3^{\circ} \mathrm{C}$ at the onset of the Younger Dryas stadial and a more rapid warming in the order of $2^{\circ} \mathrm{C}$ at the Younger DryasPreboreal transition (Lotter et al., in press). Brooks and Birks (1997) and Duigan and Birks (1997) used chironomid and cladoceran assemblages to reconstruct Younger Dryas mean summer air temperatures at Kråkenes, a site in western Norway (Birks et al., 1996), where the Younger Dryas cooling was inferred to be about $2^{\circ} \mathrm{C}$.

\section{Conclusions}

(1) Most of the chironomid taxa (67-76\%) show unimodal responses to temperature, but a number of taxonomic units have sigmoidal responses (5-22\%) or showed no relationship (7-28\%) to July temperature.

(2) The July temperature optima estimated on the basis of North American, European, and combined training sets were similar and highly correlated. Other species parameters (i.e. tolerances and regression coefficients) tended also to be similar, but much less highly correlated.

(3) The processes of taxonomic harmonization and merger of the two training sets did not greatly affect the predictive power of the models. The combined, inter-regional model consistently predicted the temperatures at the European and North American sites better than each single, regional temperature inference model did for lakes on the other continent.

(4) Two-component WA-PLS models were consistently identified by $r_{\text {(jack) }}^{2}$ and $\operatorname{RMSEP}_{(\text {jack })}$ as being superior to other WA, WA-PLS, PLS, and MAT models. However, when the European training set was used to infer North American temperatures, and vice versa, other models provided better temperature inferences.

(5) The various inference models were able to provide good July temperature inferences, even for sites on 
European Set North American Set Combined Set
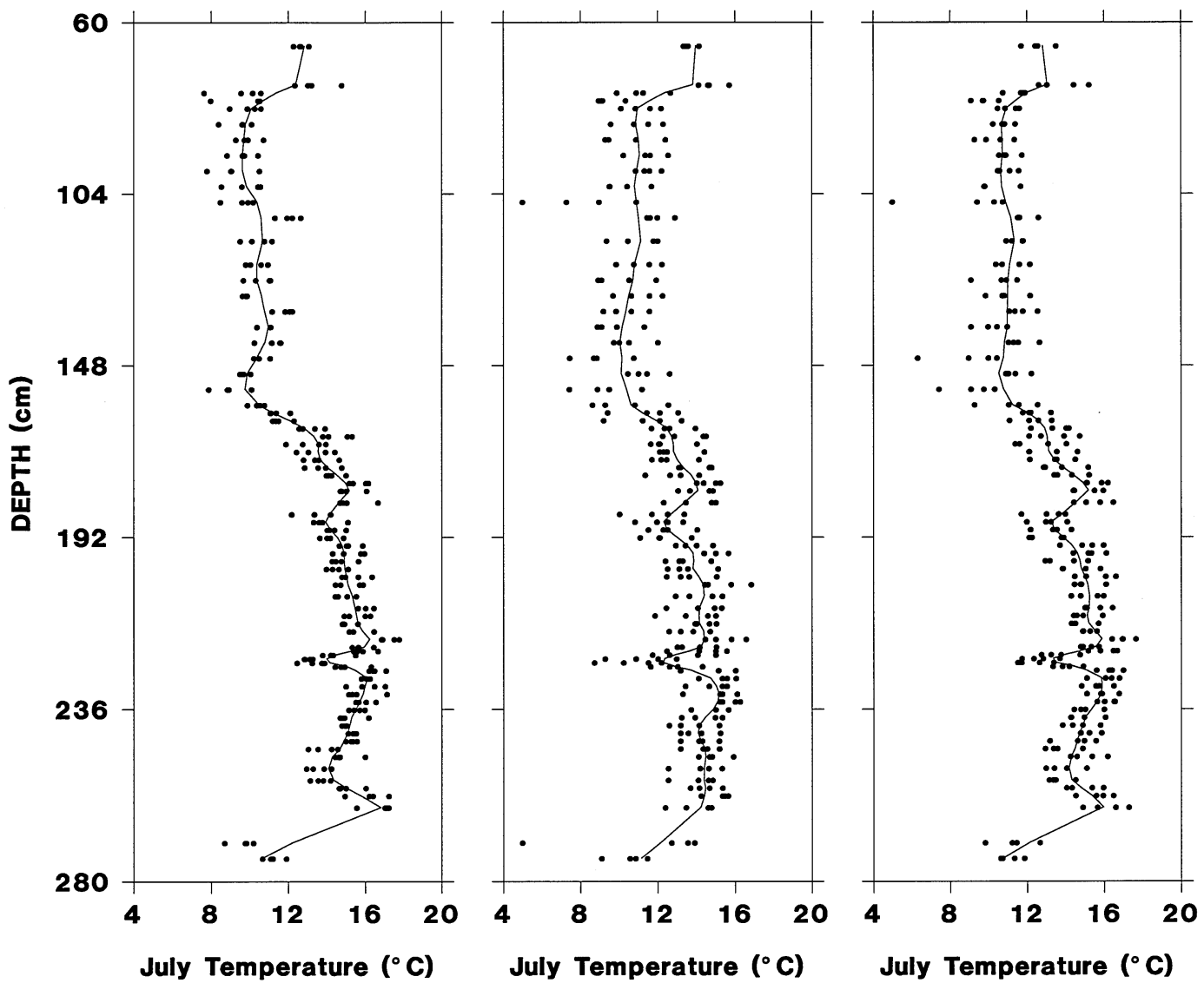

Fig. 10. Comparison of the chironomid inferred July temperature for the Lateglacial of Whitrig Bog. For each training set a combined reconstruction has been carried out based on the inferences of the four models shown in Fig. 8. A LOWESS smoother was fitted through the data points.

the other continent, and where neither good nor close analogues existed. Inferences for no analogue samples were as good as those for samples having close or good analogues.

(6) When the models were applied to fossil Lateglacial data from North America and Europe, the inferred rates and magnitude of July temperature changes varied among models; however, all models revealed similar patterns of Lateglacial temperature change. This suggests that the chironomid temperature inference models provide robust means for inferring past climatic change.

\section{Acknowledgements}

We would like to thank S. Juggins for allowing us to use his unpublished inference software, and H. J. B. Birks and S. Juggins for many discussions on inference models and quantitative reconstruction of past environments. S. Juggins and an anonymous reviewer made valuable comments on an earlier version of the manuscript.
This study has been supported by the Swiss NSF (project 5001-44600), as well as via a Natural Sciences and Engineering Research Council of Canada Research Grant and a Hans Sigrist Stiftung scholarship awarded to IRW.

\section{References}

Ammann, B., \& Lotter, A. F. (1989). Late-Glacial radiocarbon- and palynostratigraphy on the Swiss Plateau. Boreas, 18, 109-126.

Birks, H. J. B. (1994). The importance of pollen and diatom taxonomic precision in quantitative palaeoenvironmental reconstructions. Review of Palaeobotany and Palynology, 83, 107-117.

Birks, H. J. B. (1995). Quantitative palaeoenvironmental reconstructions. In D. Maddy, \& J.S. Brew (Eds.), Statistical modelling of Quaternary science data (pp. 161-254). Cambridge: Quaternary Research Association.

Birks, H. J. B. Numerical tools in fine-resolution palaeolimnology — progress, potentialities, and problems. Journal of Paleolimnology (in press).

Birks, H. J. B., Line, J. M., Juggins, S., Stevenson, A. C., \& ter Braak, C. J. F. (1990). Diatoms and $\mathrm{pH}$ reconstruction. Philosophical Transactions Royal Society London, B 327, 263-278. 
Björck, S., Kromer, B., Johnsen, S., Bennike, O., Hammarlund, D., Lemdahl, G., Possnert, G., Rasmussen, T.L., Wohlfarth, B., Hammer, C.U., \& Spurk, M. (1996). Synchronized terrestrial-atmospheric deglacial records around the North Atlantic. Science, 274, $1155-1160$

Brooks, S. J., Mayle, F. E., \& Lowe, J. J. (1997a). Chironomid-based Lateglacial climatic reconstruction for southeast Scotland. Journal of Quaternary Science, 12, 161-167.

Brooks, S. J., Mayle, F. E., \& Lowe, J. J. (1997b). The Late Devensian Lateglacial palaeoenvironmental record from Whitrig Bog, SE Scotland. 2. Chironomidae (Insecta: Diptera). Boreas, 18, 297-308.

Brooks, S. J., \& Birks, H. J. B. (1997). Chironomidae from a laminated lake in Norway: a sensitive archive of Lateglacial palaeoenvironments. Würzburger Geographische Manuskripte, 41, 43-44.

Dansgaard, W., White, J. W. C., \& Johnsen, S. J. (1989). The abrupt termination of the Younger Dryas climate event. Nature, 339, $532-534$.

Duigan, C. A., \& Birks, H. H. (1997). Reconstructing temperature changes from cladoceran microfossil assemblages at the late-glacial site of Kråkenes, Western Norway. Würzburger Geographische Manuskripte, 41, 63-64.

Hann, B. J., Warner, B. G., \& Warwick, W. F. (1992). Aquatic invertebrates and climate change: a comment on Walker et al. (1991). Canadian Journal of Fisheries \& Aquatic Sciences, 49, 1274-1276.

Hill, M. O. (1973). Diversity and evenness: a unifying notation and its consequences. Ecology, 54, 427-432.

Houde, A. (1978) Atlas climatologique du Québec: température-precipitation. Québec: Service de la Météorologie, Ministère des richesses naturelles,.

Huisman, J., Olff, H., \& Fresno, L. F. M. (1993). A hierarchical set of models for species response analysis. Journal of Vegetation Science, 4, 37-46.

Johnsen, S. J., Dahl-Jensen, D., Dansgaard, W., \& Gundestrup, N. (1995). Greenland palaeotemperatures derived from GRIP bore hole temperature and ice core isotope profiles. Tellus, 47B, 624-629.

Jones, V. J., \& Juggins, S. (1995). The construction of a diatom-based chlorophyll $a$ transfer function and its application at three lakes on Signy Island (maritime Antarctic), subject to differing degrees of nutrient enrichment. Freshwater Biology, 34, 433-445.

Jouzel, J., Lorius, C., Johnsen, S., \& Grootes, P. (1994). Climate instabilities: Greenland and Antarctic records. C.R. Acad. Sci. Paris, II, $65-77$.

Levesque, A. J., Mayle, F. E., Walker, I. R., \& Cwynar, L. C. (1993). The Amphi-Atlantic Oscillation: a proposed late-glacial climatic event. Quaternary Science Reviews, 12, 629-643.

Line, J. M., ter Braak, C. J. F., \& Birks, H. J. B. (1994). WACALIB version 3.3 - a computer program to reconstruct environmental variables from fossil assemblages by weighted averaging and to derive sample-specific errors of prediction. Journal of Paleolimnology, 10, 147-152.

Livingstone, D. M., \& Lotter, A. F. (1998). The relationship between air and water temperatures in lakes of the Swiss Plateau: a case study with palaeolimnological implications. Journal of Paleolimnology, 19, 181-198.

Lotter, A. F., Eicher, U., Birks, H. J. B., \& Siegenthaler, U. (1992). Lateglacial climatic oscillations as recorded in Swiss lake sediments. Journal of Quaternary Science, 7, 187-204.

Lotter, A. F., Birks, H. J. B., Hofmann, W., \& Marchetto, A. (1997). Modern diatom, cladocera, chironomids, and chrysophyte cyst assemblages as quantitative indicators for the reconstruction of past environmental conditions in the Alps. I. Climate. Journal of Paleolimnology, 18, 395-420.

Lotter, A. F., Birks, H. J. B., Eicher, U., Hofmann, W., Schwander, J., \& Wick, L. Younger Dryas and Allerød summer temperatures at Gerzensee (Switzerland) inferred from fossil pollen and cladoceran assemblages. Palaeogeography, Palaeoclimatology, Palaeoecology (in press).

McCalla, R. J. (1991). The Maritime Provinces Atlas. Maritext, Halifax. $96 \mathrm{pp}$.

Munro, M. A. R., Kreiser, A. M., Battarbee, R. W., Juggins, S., Stevenson, A. C., Anderson, N. J., Berge, F., Davis, R. B., Flower, R. J, Fritz, S. C., Haworth, E. Y., Jones, V. J., Kingston, J. C., \& Renberg, I. (1990). Diatom quality control and data handling. Phil. Trans. $R$. Soc. Lond. B, 327, 257-261.

Olander, H., Korhola, A., \& Blom, T. (1997). Surface sediment Chironomidae (Insecta: Diptera) distributions along an ecotonal transect in subarctic Fennoscandia: developing a tool for palaeotemperature reconstructions. Journal of Paleolimnology, 18, 45-59.

Peteet, D. M. (1992). The palynological expression and timing of the Younger Dryas event - Europe versus eastern North America. In: E. Bard, \& W. S. Broecker, (Eds.), The last deglaciation (pp. 327-344). NATO ASI Series, $I 2$. Springer: Berlin.

Rossaro, B. (1991). Chironomids and water temperature. Aquatic Insects, 13, 87-98.

Sæther, O. A. (1979). Chironomid communities as water quality indicators. Holarctic Ecology, 2, 65-74.

Taylor, K. C., Lamorey, G. W., Doyle, G. A., Alley, R. B., Grootes, P. M., Mayewski, P. A., White, J. W. C., \& Barlow, L. K. (1993). The 'flickering switch' of late Pleistocene climate change. Nature, 361, 432-436.

ter Braak, C. J. F. (1987). Ordination. In. R. H. G. Jongman, C. J. F. ter Braak, \& O. F. R. van Tongeren (Eds.), Data analysis in community and landscape ecology (pp. 91-173). Wageningen, Pudoc.

ter Braak, C. J. F., \& Juggins, S. (1993). Weighted averaging partial least squares regression (WA-PLS): an improved method for reconstructing environmental variables from species assemblages. $\mathrm{Hy}$ drobiologia, 269/270, 485-502.

ter Braak, C. J. F., Juggins, S., Birks, H. J. B., \& van der Voet, H. (1993). Weighted averaging partial least squares regression (WA-PLS): definition and comparison with other methods for species-environment calibration. In: G. P. Patil, \& C. R. Rao (Eds.), Multivariate Environmental Statistics (pp. 525-560). Elsevier, Amsterdam.

Thomas, M. K. (1953) Climatological Atlas of Canada. Ottawa: National Research Council of Canada.

Walker, I. R., \& Mathewes, R. W. (1989). Chironomid (Diptera) remains in surficial lake sediments from the Canadian Cordillera: analysis of the fauna across an altitudinal gradient. Journal of Paleolimnology, $2,61-80$.

Walker, I. R., Smol, J. P., Engstrom, D. R., \& Birks, H. J. B. (1991a). An assessment of Chironomidae as quantitative indicators of past climatic change. Canadian Journal of Fisheries and Aquatic Sciences, 48, 975-987.

Walker, I. R., Mott, R. J., \& Smol, J. P. (1991b). Allerød-Younger Dryas lake temperatures from midge fossils in Atlantic Canada. Science, $255,1010-1012$.

Walker, I. R., Smol, J. P., Engstrom, D. R., \& Birks, H. J. B. (1992). Aquatic invertebrates, climate, scale, and statistical hypothesis testing: a response to Hann, Warner, and Warwick. Canadian Journal of Fisheries and Aquatic Sciences, 49, 1276-1280.

Walker, I. R., \& MacDonald, G. M. (1995). Distributions of Chironomidae (Insecta: Diptera) and other freshwater midges with respect to treeline, Northwest Territories, Canada. Arctic and Alpine Research, 27, 258-263.

Walker, I. R., Levesque, A. J., Cwynar, L. C., \& Lotter, A. F. (1997). An expanded surface-water palaeotemperature inference model for use with fossil midges from eastern Canada. Journal of Paleolimnology, $18,165-178$. 